\title{
Interspecies Interactions in Relation to Root Distribution Across the Rooting Profile in Wheat-Maize Intercropping Under Different Plant Densities
}

\author{
Yifan Wang ${ }^{1,2}$, Yazhou Qin ${ }^{3}$, Qiang Chai ${ }^{1,2 *}$, Fuxue Feng ${ }^{1,4}$, Cai Zhao ${ }^{1,2}$ and Aizhong Yu ${ }^{1,2}$ \\ ${ }^{1}$ Gansu Provincial Key Laboratory of Arid Land Crop Science, Lanzhou, China, ${ }^{2}$ College of Agronomy, Gansu Agricultural \\ University, Lanzhou, China, ${ }^{3}$ Agricultural Shaya County Service, Xinjiang, China, ${ }^{4}$ School of Engineering, Gansu Agricultural \\ University, Lanzhou, China
}

\section{OPEN ACCESS}

Edited by:

Sudhakar Srivastava,

Banaras Hindu University, India

Reviewed by:

Richard E. Farrell,

University of Saskatchewan, Canada Guzel Kudoyarova,

Institute of Biology (CAS), Russia

*Correspondence:

Qiang Chai

chaiq@gsau.edu.cn

Specialty section:

This article was submitted to Agroecology and Land Use Systems, a section of the journal Frontiers in Plant Science

Received: 21 November 2017 Accepted: 29 March 2018 Published: 20 April 2018

Citation: Wang Y, Qin Y, Chai Q, Feng F, Zhao C and Yu A (2018) Interspecies

Interactions in Relation to Root Distribution Across the Rooting Profile in Wheat-Maize Intercropping Under Different Plant Densities.

Front. Plant Sci. 9:483 doi: $10.3389 /$ fpls.2018.00483
In wheat-maize intercropping systems, the maize is often disadvantageous over the wheat during the co-growth period. It is unknown whether the impaired growth of maize can be recovered through the enhancement of the belowground interspecies interactions. In this study, we (i) determined the mechanism of the belowground interaction in relation to root growth and distribution under different maize plant densities, and (ii) quantified the "recovery effect" of maize after wheat harvest. The three-year (2014-2016) field experiment was conducted at the Oasis Agriculture Research Station of Gansu Agricultural University, Wuwei, Northwest China. Root weight density (RWD), root length density (RLD), and root surface area density (RSAD), were measured in single-cropped maize $(M)$, single-cropped wheat $(\mathrm{W})$, and three intercropping systems (i) wheat-maize intercropping with no root barrier (i.e., complete belowground interaction, IC), (ii) nylon mesh root barrier (partial belowground interaction, IC-PRI), and (iii) plastic sheet root barrier (no belowground interaction, IC-NRI). The intercropped maize was planted at low (45,000 plants ha $\left.{ }^{-1}\right)$ and high $\left(52,000\right.$ plants ha $\left.{ }^{-1}\right)$ densities. During the wheat/maize co-growth period, the IC treatment increased the RWD, RLD, and RSAD of the intercropped wheat in the $20-100 \mathrm{~cm}$ soil depth compared to the IC-PRI and IC-NRI systems; intercropped maize had 53\% lower RWD, 81\% lower RLD, and 70\% lower RSAD than single-cropped maize. After wheat harvest, the intercropped maize recovered the growth with the increase of RWD by $40 \%$, RLD by $44 \%$ and RSAD by $11 \%$, compared to the single-cropped maize. Comparisons among the three intercropping systems revealed that the "recovery effect" of the intercropped maize was attributable to complete belowground interspecies interaction by $143 \%$, the compensational effect due to root overlap by $35 \%$, and the compensational effect due to water and nutrient exchange (CWN) by $80 \%$. The higher maize plant density provided a greater recovery effect due to increased RWD and RLD. Higher maize plant density stimulated greater belowground interspecies interaction that promoted root growth and development, strengthened the recovery effect, and increased crop productivity.

Keywords: intercropping, interspecies interaction, plant density, root weight density, root length density, root surface area density, recovery effect, grain yield 


\section{INTRODUCTION}

Intercropping refers to a planting pattern where two or more crops are grown in alternate rows in the same field (Vandermeer, 1989). The intercropping systems have been proved to be superior to single cropping in productivity, because they promote a higher land utilization efficiency (Romero et al., 2013), optimize the use of available resources in both time and space (Fan et al., 2013; Yin et al., 2015), and reduce weed and disease pressures (Agegnehu et al., 2008). The yield advantage in intercropping systems is often obtained through the coordination of the interspecies interaction for above- and/or belowground competition ( $\mathrm{Li}$ et al., 2006). Belowground competition often takes various forms and involves complex processes (Schenk, 2006), where the intercrops may compete for available water and nutrients during the co-growth period, leading to poor performance of one crop over the other one (Wilson, 1988). However, well-coordinated interspecies interaction may result in positive outcomes due to improved resource sharing and temporal optimization for the growth of the aboveground plant parts. Therefore, understanding the interspecies interactions belowground may provide a guideline for a better coordination of the potential competition for resources for above ground plant parts.

Plant roots serve as the crucial site for belowground interspecies interactions, because roots not only absorb water and nutrients, but also synthesize and transform other trace substances to the other plant tissues (Landhäusser et al., 2006; $\mathrm{Hu}$ et al., 2009). The growth of crop roots is related to many crop management factors, such as irrigation and fertilizer management (Levangbrilz and Biondini, 2003; Ahmad et al., 2010), spatial arrangement (Wang et al., 2006; Yang et al., 2010), and plant density (Muoneke et al., 2007). Often the case that intercropped plants have higher root mass than monoculture crops (Li et al., 2006), because the overlapping of the roots of the two intercropped crops makes full use of belowground resources (Vandermeer, 1989); this belowground ecological niche separation plays a key role in determining the growth and yield of the intercrops (Li L. et al., 2011). Efforts to optimize the root growth may help regulate the interspecific relationship in the intercropping system ( $\mathrm{Li}$ et al., 2006). We proposed that manipulation of planting densities could promote a positive interspecific interaction in intercropping systems because the root mass of the intercrops is often a reflection of plant density when growth resources are sufficiently available. However, little information is available in regard to how the planting density of one intercrop may influence the root dynamics and the function of the other intercrop. Some studies have shown that increasing the density of one of the intercrops increased interspecific competition and reduced the yield of the other component crop (Beaver and Melgar, 1999; Muoneke et al., 2007). However, it is unknown if this kind of competition may occur under irrigation where competition for soil water is minimal.

Wheat/maize intercropping has been widely adopted in the primary grain production areas of Northwestern China, where the cropping system has traditionally been a single crop annually due to temperature constraints (Qin et al., 2013). Research has shown that in the intercropping system, early-planted wheat has a competitive advantage over late-planted maize ( $\mathrm{Hu}$ et al., 2016). Although the intercropped maize initially suffers growth penalties during the co-growth period due to late-planting, the maize continues to grow, after wheat harvest, until the season end with higher above- and belowground growth rates compared with single-cropped maize. In a normal growing season, intercropped maize can have a "recovery effect" (Yin et al., 2017), which is manifested in an increase in aboveground dry matter accumulation. However, it is not clear how belowground interspecies interactions may affect the recovery effect. In efforts to elucidate the mechanisms underlying the relationship between belowground interspecies interaction and the recovery effect, we used a root partitioning technique, as discussed by others (Ong, 1995). We designed three types of root barrier treatments to investigate belowground interactions: (i) no root barrier (allowing a complete belowground interaction), a nylon mesh barrier (allowing a partial belowground interaction), and a plastic sheet barrier (no belowground interspecies interaction). The intercropped maize was planted at two plant densities $(45,000$ and 52,000 plants $\mathrm{ha}^{-1}$ ). The objective of this study were to determine (i) the vertical distribution characteristics of roots in responses to different belowground interactions, (ii) the recovery effect of intercropped maize roots after wheat harvest, and (iii) the relationships between root vertical distribution and recovery effect in affecting grain yield. Our hypothesis was that complete belowground interaction under high maize density promotes root growth of the intercropped wheat and maize, strengthens the root recovery effect of maize at wheat postharvest, and thereby improving intercropping productivity.

\section{MATERIALS AND METHODS}

\section{Experimental Site}

Field experiments were carried out from 2014 to 2016 at the Wuwei Oasis Experimental Station $\left(37^{\circ} 96^{\prime} \mathrm{N}, 102^{\circ} 64^{\prime} \mathrm{E}\right.$, elev. 1,506 m.) of Gansu Agricultural University, located in the eastern region of the Hexi Corridor in Northwest China. The long-term (1960 2009) annual sunshine duration is 2,945 h, annual mean air temperature is $7.2^{\circ} \mathrm{C}$, and a frost-free period is 155 days (Chai et al., 2014). The meteorological records from the National Meteorological Information Administration of China (Beijing, China) show that the long-term mean annual precipitation is $156 \mathrm{~mm}$ with $70 \%$ occurring during the MaySeptember growing season, while annual evaporation (freewater surface) is $>2,400 \mathrm{~mm}$. In the present study, we recorded some relevant weather data using a Farmland Microclimate Automatic Monitoring System (Hangzhou, China). Sunshine duration during the study years of 2014, 2015, and 2016 was $3,004,2,837$, and $2,947 \mathrm{~h}$, respectively; average air temperature was $6.3,7.9$, and $7.0^{\circ} \mathrm{C}$; frost-free period was 162,123 , and 158 days; and annual precipitation was 245, 167, and $210 \mathrm{~mm}$, respectively (Figure 1). The precipitation during the study years was higher than the long-term averages, and this factor was considered when we determined the total amount of irrigation water applied to the crops. Temperatures in each of the study years were comparably similar to the long-term 


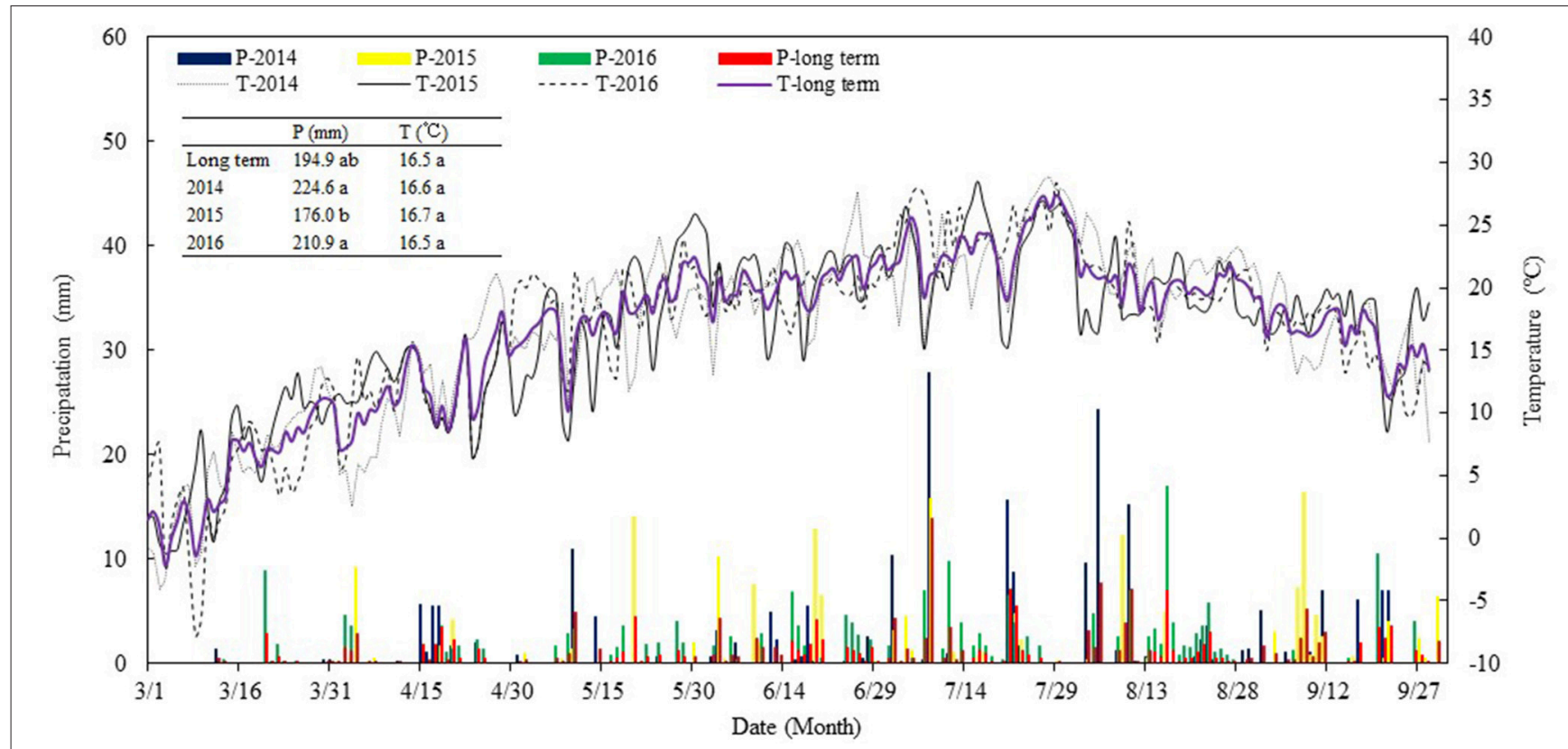

FIGURE 1 | Precipitation (P) and air temperature (T) during maize growing seasons (from 1st Mar. to 30th Sept.) in 2014, 2015, and 2016 in comparison with the long-term (from 2000 to 2017, and getting the data from the National Meteorological Information Center) averages, at Wuwei Experimental Station.

averages. Overall, the abundant sunshine and temperatures in the area are more than the need by a crop per year but are insufficient for the needs of two crops per year. Intercropping of a cool-season, earlier-maturing crop with a warm-season, later-maturing crop is ideal to enhance the use of the natural resources.

\section{Experimental Design and Plot Management}

The experiment included nine treatments that were arranged in a randomized complete block design with three replicates. Three root partitioning patterns for the wheat-maize intercropping were performed at two maize plant densities, i.e., no root barrier, a nylon-mesh barrier, and a plastic sheet barrier, each at the low (45,000 plants ha $\left.{ }^{-1}\right)$ and high $\left(52,500\right.$ plants $\left.\mathrm{ha}^{-1}\right)$ plant densities. Corresponding monoculture treatments included single-cropping maize at the plant densities of 90,000 and 105,000 plants $\mathrm{ha}^{-1}$, and single-cropping wheat at the density of $6,750,000$ plants $\mathrm{ha}^{-1}$. The intercropped wheat was at 3,750,000 plants $\mathrm{ha}^{-1}$. The maize plant densities were ensured using an inhouse maize planter where the distance between plants within a row was justified according to the density. The wheat density was ensured with a rate of viable seed per area based on seed size, germination rate, and field emergence rate. To simplify the presentation, we designated the wheat-maize intercropping with no root barrier at the low and high plant densities as IC1 and IC2 where "IC" representing "Intercropping" and the numbers followed as the low (1) and high (2) maize plant densities, respectively; thus, the wheat-maize intercropping with nylon-mesh root barrier (Partial root interaction) at the low and high densities was designated as IC-PRI1 and IC-PRI2; and the wheat-maize intercropping with a plastic sheet barrier
(No belowground interaction) at the low and high densities as IC-NRI1 and IC-NRI2; single maize cropping at the low and high densities as M1 and M2, and single wheat cropping as W. The plant densities used in the experiment were based on the results of previous studies conducted at the area ( $\mathrm{Li}$ et al., 2001b; Hu et al., 2014).

A scheme of the field layout is shown in Figure 2. Each plot was $8 \mathrm{~m}$ long $\times 4.8 \mathrm{~m}$ wide in size. In the intercropping treatments, wheat and maize were planted in alternate strips with six rows of wheat (12-cm row spacing) alternated with two rows of maize (40-cm row spacing). Each plot contained three sets of wheat and maize strips. Prior to sowing, a trench ( $1 \mathrm{~m}$ deep, $0.1 \mathrm{~m}$ wide, and $8 \mathrm{~m}$ long) was made manually between the two crop strips, and the root barrier materials (nylon mesh with 300 micropores $\mathrm{cm}^{-2}$, or a flexible plastic sheet in $0.12 \mathrm{~mm}$ thickness) were vertically inserted into each trench and then filled with the excavated soil.

The sowing date and growth periods of spring wheat (cultivar Yong-Liang no. 4) and maize (cultivar Xian-Yu 335) are summarized in Table 1. All the strips of maize were covered with white plastic film at sowing, a practice widely adopted in the arid and semiarid northwest China for boosting maize productivity (Gan et al., 2013). Single wheat and single maize cropping received urea $\mathrm{N}$-fertilizer at the rate of 225 and $450 \mathrm{~kg}$ $\mathrm{N} \mathrm{ha}{ }^{-1}$, respectively; and phosphorus oxide $\left(\mathrm{P}_{2} \mathrm{O}_{5}\right)$ at 150 and $225 \mathrm{~kg} \mathrm{P} \mathrm{ha}^{-1}$, respectively. The fertilizer rates for the intercrops were the same as those for the single crops per area basis. Both $\mathrm{N}$ and $\mathrm{P}$ were applied at seeding for wheat, while a split application was used for maize crops, with $135 \mathrm{~kg} \mathrm{~N} \mathrm{ha}^{-1}$ and $67.5 \mathrm{~kg} \mathrm{P} \mathrm{ha}^{-1}$ applied at seeding, $270 \mathrm{~kg} \mathrm{~N} \mathrm{ha}^{-1}$ and $135 \mathrm{~kg} \mathrm{P} \mathrm{ha}^{-1}$ at stem elongation, and $45 \mathrm{~kg} \mathrm{~N} \mathrm{ha}^{-1}$ and $22.5 \mathrm{~kg} \mathrm{P} \mathrm{ha}^{-1}$ at grain filling. 


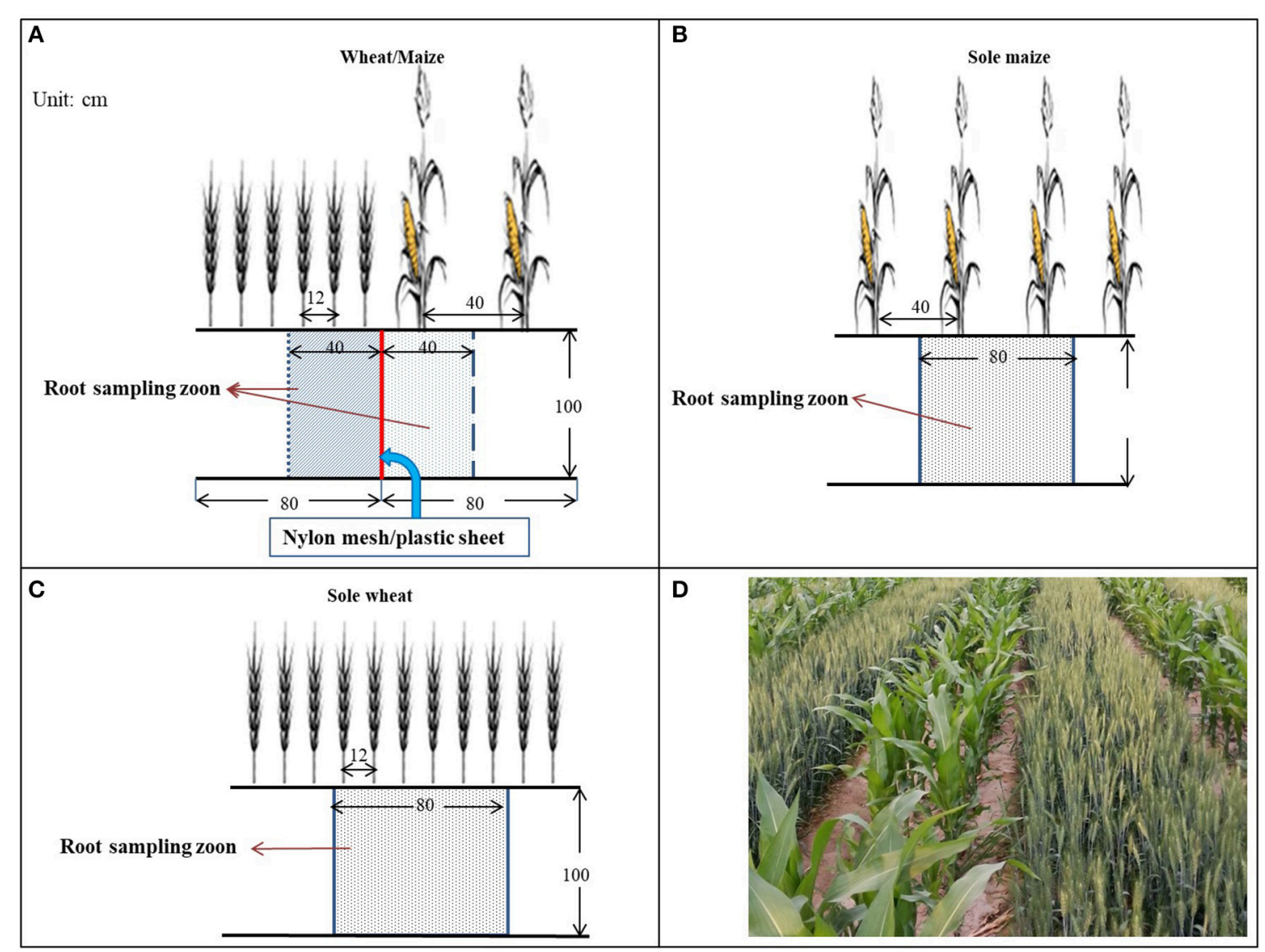

FIGURE 2 | Layout of intercrops and the partition of roots in the wheat/maize intercropping system, with (A) wheat/maize intercropping with an 80-cm strip of wheat (six rows) alternated with an 80-cm strip of maize (two rows) in comparison with (B) single maize and (C) single wheat cropping. In the wheat/maize intercropping (A), three root barrier treatments were included: (i) without a physical barrier (IC), (ii) with a nylon mesh barrier (IC-PRI), and (iii) with a solid plastic sheet (IC-NRI) inserted between wheat and maize strips. Nylon mesh and plastic sheet were placed vertically to the depth of $100 \mathrm{~cm}$. The shadow section is the root sampling zone, and (D) shows the co-growth period of the wheat/maize strip intercropping in northwestern China.

TABLE 1 | Phenological stages of maize and wheat plants, at Wuwei Experimental Station, China, 2014, 2015, and 2016.

\begin{tabular}{|c|c|c|c|c|c|c|}
\hline Year & Crop & Sowing & Stem elongation/branching & Flowering/tasseling & Filling & Harvesting \\
\hline \multirow[t]{2}{*}{2014} & Maize & Apr $22^{a}$ & Jun 14 & Jul 15 & Aug 12 & Oct 4 \\
\hline & Wheat & Mar 22 & May 3 & Jun 18 & Jun 26 & Jul 26 \\
\hline \multirow[t]{2}{*}{2015} & Maize & Apr 25 & Jun 16 & Jul 16 & Aug 12 & Sep 28 \\
\hline & Wheat & Mar 28 & May 5 & Jun 18 & Jun 26 & Jul 27 \\
\hline \multirow[t]{2}{*}{2016} & Maize & Apr 23 & Jun 16 & Jul 19 & Aug 14 & Sep 20 \\
\hline & Wheat & Mar 29 & May 7 & Jun 16 & Jun 20 & Jul 22 \\
\hline
\end{tabular}

a The dates of the phonological stage were recorded when $75 \%$ of the plants in a plot had developed to the particular growth stage.

The fertilization at seeding was implemented by broadcasting them on the soil surface and then incorporated to the soil using a shallow rotary tillage. Top-dressing fertilizers during the growth stages were implemented by making a hole of $10-15 \mathrm{~cm}$ deep and 5-6 cm away from the plant, a pre-determined amount of fertilizers was placed in the hole and the hole was filled with the soil. Crops were irrigated multiple times during the growing season (Table 2).

\section{Root Sample Collection}

In arid and semiarid areas, the root growth of spring wheat often reaches the peak at flowering and then the rate of the growth may level off or decline. During the vigorous growth period, intercropped wheat plants have a competitive advantage for resources over the intercropped maize due to the earlier sowing of wheat than maize. However, after wheat harvest, a rapid recovery of the growth of the intercropped maize is highly expected due 
TABLE 2 | The dates and the amounts of irrigation water applied to the wheat and maize, at Wuwei Experimental Station, China, 2014, 2015, and 2016.

\begin{tabular}{|c|c|c|c|c|c|c|}
\hline \multirow{2}{*}{$\frac{\text { Year }}{2014}$} & \multicolumn{6}{|c|}{ Irrigation date } \\
\hline & May 5 & May 30 & Jun 20 & Jul 30 & Aug 19 & Sep 5 \\
\hline 2015 & May 9 & May 28 & Jun 21 & Jul 30 & Aug 16 & Sep 3 \\
\hline 2016 & May 8 & May 27 & Jun 16 & Aug 1 & Aug 18 & Sep 2 \\
\hline Cropping pattern ${ }^{a}$ & \multicolumn{6}{|c|}{ Irrigation amount in each year $\left(\mathrm{m}^{3} \mathrm{ha}^{-1}\right)$} \\
\hline W & 750 & 900 & 750 & 0 & 0 & 0 \\
\hline M & 750 & 900 & 750 & 900 & 750 & 750 \\
\hline IC & 750 & 900 & 750 & 900 & 750 & 750 \\
\hline
\end{tabular}

${ }^{a} W$, single-cropped wheat; $M$, single-cropped maize; IC, intercropped wheat/maize. The total amount of irrigation water is the sum of all irrigations during the entire growing season, i.e., the total amount was 2,400 $\mathrm{m}^{3} \mathrm{ha}^{-1}$ for single-cropped wheat, 4,800 $\mathrm{m}^{3} \mathrm{ha}^{-1}$ for single-cropped maize, and 4,800 $\mathrm{m}^{3} \mathrm{ha}^{-1}$ for the wheat-maize intercropping.

to more space and resources are available. Positive outcome of the growth recovery of intercropped maize can be realized during the grain filling period. Studies have shown large differences in maize root growth during grain filling compared with during the co-growth period (Li et al., 2001b). Therefore, in the present study, we sampled plant roots at wheat flowering and maize stem elongation stage $(\mathrm{BCCH}$ scale $=30)$ on 14 June in 2014, 17 June in 2015, and 12 June in 2016 for the first sampling. The second sampling was at the maize grain-filling stage $(\mathrm{BCCH}=71)$ on 8 August in 2014, 11 August in 2015, and 13 August in 2016.

Plant roots were sampled using a modified monolith method (Smit et al., 2000) in the following three steps. First - preparing sampling trenches. A trench $(100 \mathrm{~cm}$ long, $60 \mathrm{~cm}$ wide, and $120 \mathrm{~cm}$ deep) was made manually in each plot, with the direction of the trench length perpendicular to the crop row. Each trench covered an area of three rows of wheat and one row of maize in intercropping, or six rows of wheat or two rows of maize in the monoculture planting patterns. The readily-made trench provided sufficient space that allowed the sampler to work directly with the root-soil matrix with sampling tools. Secondmarking the monoliths. The surface of the root-soil profile was smoothed by hand, and the size of each monolith to be sampled was marked on the profile wall using color makers. Each rootsoil monolith was $40 \mathrm{~cm}$ long $\times 20 \mathrm{~cm}$ wide $\times 20$ deep for each of the two intercrops, whereas it was $80 \mathrm{~cm}$ long $\times 20 \mathrm{~cm}$ wide $\times 20$ deep for the monoculture planting patterns. The marking system clearly depicted the five monoliths to be sampled in each root-soil profile. For the intercropping, the five monoliths were marked in the intercropped wheat and the other five in the intercropped maize. Each monolith had a depth of $20 \mathrm{~cm}$, and thus, the five monoliths had the total depth of $100 \mathrm{~cm}$ (Figure 2). Third-taking the monoliths. From the top layer of the profile, each monolith was cut following the marked lines using a sharp knife, a metal sheet sharpened on one side was inserted horizontally $40 \mathrm{~cm}$ onward into the profile, and the entire monolith was taken.

\section{Root Weight Density, Root Length Density, and Root Surface Density}

Each root-soil monolith was placed in a $0.2-\mathrm{mm}$ mesh bag, soaked in water for $1 \mathrm{~h}$, gently stirred, and hand-scrubbed to clean the soil. The remaining debris was removed from the roots by hand. In wheat and maize intercropping with no root barrier, some monoliths contained the roots of both wheat and maize plants, and therefore it was necessary to distinguish between wheat and maize roots based on their visual appearance. Maize roots mostly had a larger diameter than wheat roots and some fine maize roots were yellowish, fragile, and with some visible nodes. The separated root fractions were placed into valve bags and brought to the laboratory. Root length and root surface area were immediately measured using an EPSON scanner in conjunction with Win-RHIZO ${ }^{\mathrm{TM}}$ image analysis software (Régent Instruments Inc., Québec, Canada). The roots were then oven baked for $30 \mathrm{~min}$ at $105^{\circ} \mathrm{C}$ to deactivate enzymes, and thereafter were dried at $80^{\circ} \mathrm{C}$ until a constant weight and weighed for biomass with an accuracy of $0.001 \mathrm{~g}$. Finally, the root weight density (RWD: grams of dry root weight per cubic centimeter of the monolith), root length density (RLD: centimeter of root length per cubic centimeter), and root surface area density (RSAD: square centimeter of root surface area per cubic centimeter) were calculated from the volume of the soil monolith using the following formulae:

$$
\begin{gathered}
R W D=R W / S V \\
R L D=R L / S V \\
R S A D=R S A / S V
\end{gathered}
$$

where $R W$ is root dry weight, $R L$ is root length, $R S A$ is root surface area, and $S V$ is soil volume. Due to the sample size, the soil volume of the intercropped wheat and intercropped maize each was $16,000 \mathrm{~cm}^{3}$, whereas the volume of single-cropped wheat and maize each was $32,000 \mathrm{~cm}^{3}$.

For each of the three replicates, the total RWD of the 0-100$\mathrm{cm}$ soil layer was the sum of the weight of the roots from each of the depths and divided by the combined volume of the individual compartments. The average was based on the three replicates. The calculation of the averages of RLD and RSAD was the same as that used for the calculation of RWD.

\section{Methods for Calculating Indices Recovery Effect}

Interspecific competition may occur when two crops are grown together or in neighboring strips (Vandermeer, 1989). Such competition generally decreases the growth of at least one of the intercropped species (Yin et al., 2017). In the case of wheatmaize intercropping, the wheat often inhibits the growth of maize during the co-growth period. After harvest of the early-maturing wheat, the remaining intercropped maize accelerates the growth to form a compensatory growth period. The recovery process in maize plant growth could offset the impaired early growth occurring during the co-growth period (Zhang and Li, 2003; Li L. et al., 2011). The roots of the intercropped maize that occupy a large belowground space may play an important role in the recovery growth (Li L. et al., 2011). In the present study, we defined the recovery effect of the intercropped maize (RE) as the differences of the root growth rate between the intercropped 
maize and the corresponding monoculture maize as follow:

$$
R E=R G R_{I} / R G R_{M}
$$

where $R G R_{I}$ is the root growth rate of the intercrops, and $R G R_{M}$ is the root growth rate of the monoculture maize.

The root growth rate was defined as:

$$
R G R=\left(R_{2}-R_{1}\right) /\left(t_{2}-t_{1}\right)
$$

where $R_{2}$ and $R_{1}$ is the root traits measured at the two consecutive time $t_{2}$ and $t_{1}$, respectively. The $t_{2}$ sampling was at the maize filling stage and the $t_{1}$ sampling was at the wheat flowering stage or at the maize stem elongation stage. The calendar dates of samplings differed slightly each year and were detailed in Table 1. The RGR was determined for each of the three key root traits: RWD, RLD, and root surface area density, in the $0-100 \mathrm{~cm}$ profile. An RE value $>1.0$ indicates that intercropped maize had a recovery effect after the harvest of the co-cropped wheat (Yin et al., 2017).

\section{Grain Yield, Biomass, and Harvest Index}

For both single-cropping and the intercropping systems, the maize and wheat in each plot was hand-harvested at full maturity, and the samples of grains and straw were air dried, cleaned, and weighed to determine grain and biomass yields (BYs), respectively. The percentage of yield increase of intercropping compared with sole cropping is equal to the total yield of intercropping system divided by the yield of the corresponding sole crops. All yields were expressed on a per unit area basis. The term "overyielding" was used to quantify the magnitude of the yield increase for each of the two intercrops over the corresponding sole crops.

Overyielding for grain was calculated by following the formula developed by Li Q. Z. et al. (2011):

$$
\text { Overyielding }(\%)=\frac{Y_{\text {intercrop }}-Y_{\text {solecrop }} \times \operatorname{Pr}}{Y_{\text {solecrop }} \times \operatorname{Pr}} \times 100
$$

where $Y_{\text {Intercrop }}$ is the yield of the intercrop (wheat or maize), $Y_{\text {solecrop }}$ is the yield of sole crop (wheat or maize), $P r$ is the land area occupied by each intercrop in proportion to total area. In this study, the $P r_{\text {wheat }}=P r_{\text {maize }}=50 \%$. Overyielding for the intercropping was assessed by an increase or decrease in the intercropped crops over the corresponding single crop. A positive overyielding indicates a yield advantage for the intercropping over the corresponding single crop.

The harvest index (HI) was determined by dividing the grain yield (GY) by the aboveground biomass yield (BY) per unit area.

$$
H I=G Y / B Y
$$

\section{Three Root Barrier Treatments and Possible Interspecific Interactions}

The three aforementioned root barrier treatments were implemented in each year. The no-barrier treatment allowed intercrop roots to penetrate into neighboring strips and freely exchange water and nutrients, whereas the nylon mesh barrier physically blocked root penetration but allowed potential movement of water and nutrients between the plant rows. In contrast, in the plastic sheet barrier treatment, the solid plastic sheet separated the two intercrops physically, preventing any belowground interspecies interaction. Therefore, a comparison between the no barrier (complete belowground interaction, IC) and plastic sheet barrier (no root interaction, only aboveground interaction, IC-NRI) treatments enabled us to determine the contribution of belowground interspecific interaction. Similarly, a comparison between the no barrier (IC) and nylon mesh barrier (partial belowground interaction, IC-PRI) treatments enabled us to determine the compensational effect due to root overlap between the two intercrops; a comparison between nylon-mesh barrier (IC-PRI) and plastic sheet barrier (IC-NRI) treatments enabled us to determine the compensational effect due to water and nutrient exchange (CWN).

To quantify the belowground interspecies interaction, we determined the contribution rate of belowground interaction (CRB) as follows:

$$
C R B(\%)=\frac{Y_{I C}-Y_{I C-N R I}}{Y_{I C-N R I}} \times 100
$$

where $Y_{I C}$ and $Y_{I C-N R I}$ are the GY or recovery effect of intercropping without a barrier and intercropping with a plastic sheet barrier, respectively.

The compensational effect due to root overlapping (CRO) was calculated as follows:

$$
C R O(\%)=\frac{Y_{I C}-Y_{I C-P R I}}{Y_{I C-P R I}} \times 100
$$

where $Y_{I C}$ and $Y_{I C-P R I}$ are the GY or recovery effect of intercropping without a barrier and intercropping with a nylon mesh barrier, respectively.

The CWN was calculated as follows:

$$
C W N(\%)=\frac{Y_{I C-P R I}-Y_{I C-N R I}}{Y_{I C-N R I}} \times 100
$$

where $Y_{I C-P R I}$ and $Y_{I C-N R I}$ are the same as defined above.

\section{Statistical Analysis}

The data were analyzed using the Statistical Package for Sciences statistical analysis software (SPSS software, 19.0; SPSS Inst. Ltd., USA). Two-way analysis of variance (ANOVA) followed by the Fisher Protected Least Significance Difference (LSD) test was performed to determine the main effects (belowground interaction pattern and maize density) and their interactions on the variables RWD, RLD, RSAD, RE, and GY. When belowground interaction pattern $\times$ plant density interaction effect was not significant, the means of belowground interaction patterns and the means of densities were presented; however, when belowground interaction pattern $\times$ density interaction was significant, the belowground interaction effect was determined for each of the two maize density levels, and density effect was determined at each of the three belowground interaction treatments. The significances between treatments 
were determined using the LSD multiple-range test at the 0.05 probability level. Due to significant treatment by year interactions for most of the variables, the treatment effects are presented separately for each year. However, the root growth rate and recovery effect are presented as the 3-year averages because they did not differ significantly between the study years.

\section{RESULTS}

\section{Wheat Root Development in Relation to Belowground Interaction During the Co-growth Period}

Wheat roots were sampled in mid-June each year, which coincided with a time when the wheat plants were at the midflowering stage (Figure 3). During this period, most of wheat roots were distributed in the $0-20$ and $20-40-\mathrm{cm}$ soil layers. For single-cropped wheat, $72 \%$ of roots were distributed in the $0-20-\mathrm{cm}$ soil layer and $11 \%$ in the $20-40-\mathrm{cm}$ soil layer, whereas for intercropped wheat, $57 \%$ of roots were distributed in the $0-20-\mathrm{cm}$ soil layer and $20 \%$ were in the $20-40-\mathrm{cm}$ soil layer. Wheat in the treatments IC-PRI (partial belowground interaction) and IC-NRI (without belowground interaction) had lower total RWD, RLD, and root surface area (RSAD) compared with single-cropped wheat in the $0-100-\mathrm{cm}$ soil layer. However, single-cropped wheat and the intercropped wheat in the complete belowground interaction (IC, without root barrier) had similar total $(0-100 \mathrm{~cm}) \mathrm{RLD}$, and RSAD. The IC treatment had a lower RWD in the $0-20-\mathrm{cm}$ soil layer than the single-cropped wheat, but the former had a significantly higher RWD than the singlecropped wheat in the $20-100 \mathrm{~cm}$ soil layer.

The treatment $\times$ year interaction was significant for RWD most likely due to the complex nature of many soil layers in which the measurements were taken. However, the trend of the treatment effects was similar across the 3 study years (Figure 3 ). Also, maize density had no effect on the RWD of the intercropped wheat. Thus, the averages of the treatment effects over the two densities across the three years were discussed. The IC treatment with complete belowground interaction increased the RWD of intercropped wheat significantly. In the 0-20, 20-40, 40-60, 6080 , and $80-100-\mathrm{cm}$ soil layers, the IC treatment increased RWD by $45,36,231,131$, and $222 \%$, respectively, compared with the IC-NRI treatment; and the value of the increase was 16, 16, 142, 63 , and $78 \%$ compared with the IC-PRI treatments.

Maize density had no effect on the RLD of the intercropped wheat (Figure 3). The IC treatment increased the RLD of intercropped wheat compared with the IC-PRI and IC-NRI treatments. In the $0-20,20-40$, and $40-60-\mathrm{cm}$ soil layer, the IC treatment increased wheat RLD by 69,43 , and $44 \%$ in 2014 and by 9,72 , and $11 \%$ in 2016, compared with the IC-NRI treatment. However, no differences were found between those intercropping treatments in 2015 . In the $60-80$ and $80-100-\mathrm{cm}$ soil layers, the IC treatment increased wheat RLD by 37 and $50 \%$ in 2014 and by 11 and $20 \%$ in 2015, compared with IC-NRI treatment, with no differences found in 2016. Similarly, in the 0-20-cm soil layer, wheat RLD was improved by $29 \%$ in 2014 and by $25 \%$ in 2015 under the IC treatment, compared with the IC-PRI treatment, but no difference was found in 2016. In the 20-40 and 40-60$\mathrm{cm}$ soil layers, wheat RLD was improved by 38 and 13\% in 2015 and by 44 and $37 \%$ in 2016 under IC treatment, compared with the IC-PRI treatment, with no differences found in 2015. In the $60-100 \mathrm{~cm}$ soil layer, there was no significant difference between IC and IC-PRI treatment.

Maize density had no effect on the RSAD of the intercropped wheat (Figure 3). The RSAD of intercropped wheat was reduced by $20 \%$ in 2015 and $10 \%$ in 2016 under IC treatment, compared with that in the IC-NRI treatment, with no difference found in 2014. However, on three year average, in the 20-40, 40-60, 6080 , and $80-100-\mathrm{cm}$ soil layers, wheat RSAD in the IC treatment was, respectively, 51, 42, 54, and $65 \%$ greater than wheat in the IC-NRI; and was, respectively, 11, 17, 37, and $32 \%$ greater than wheat in the IC-PRI treatment.

\section{Maize Root Development in Relation to Belowground Interactions During the Co-growth Period}

Maize roots were sampled at the beginning of stem elongation $(\mathrm{BBCH}=30)$, a time when the intercropped wheat was at the mid-flowering stage (Figure 4). At this stage, about $70 \%$ of the roots in single-cropped maize were distributed in the $0-$ $20-\mathrm{cm}$ soil layer and about $20 \%$ in the $20-40-\mathrm{cm}$ soil layers, whereas about $60 \%$ of the roots in the intercropped maize were distributed in the $0-20 \mathrm{~cm}$ soil layer and about $20 \%$ in the $20-$ $40-\mathrm{cm}$ soil layers. Single-cropped maize had higher total RWD, $\mathrm{RLD}$, and RSAD than the intercropped maize in most of the soil layers. Single-cropped maize had higher total RWD, RLD, and RSAD compared with the intercropped maize in the 0$100-\mathrm{cm}$ soil layer. Averaged over the three years, single-cropped maize increased total RWD, RLD, and RSAD by 53,81 , and $70 \%$, respectively, than the maize in the IC treatment; the values of the increases were 49,96 , and $109 \%$ compared with the maize in the IC-PRI treatment, and were 43,69 , and $82 \%$ compared with the maize in the IC-NRI treatments.

The three belowground interaction treatments had significant effects on the RWD of intercropped maize in most of the soil layers (Figure 4). In the $0-20-\mathrm{cm}$ soil layer, the maize RWD in the IC treatment was $45 \%$ greater than that in the IC-NRI treatment in 2014 and $18 \%$ greater in 2016, but no difference was found in 2015. In the $60-80$ and $80-100-\mathrm{cm}$ soil layers, the IC treatment increased maize RWD by 117 and 183\%, respectively for the two soil depths in 2014 and 38 and 145\% in 2015, compared with those in the IC-NRI treatment. However, in 2016, maize RWD did not differ between the treatments. In the 0-20 and $20-40 \mathrm{~cm}$ soil layers, the IC treatment increased maize RWD by $25 \%$ and $126 \%$, respectively for the two soil depths in 2014 and 13 and $13 \%$ in 2016, but no differences were found in 2015, as compared with those in the IC-PRI treatment. Also, in the 40$60,60-80$, and $80-100-\mathrm{cm}$ soil layers, the IC treatment increased the maize RWD by 35,103 , and $240 \%$, respectively in 2014 ; 35,26 , and $36 \%$ in 2015 , compared with the IC-PRI treatment, but no differences were found in 2016. Maize plant density had an interactive effect on maize RWD. With the maize density increase from the low to high, the RWD in the 20-40, 40-60, 

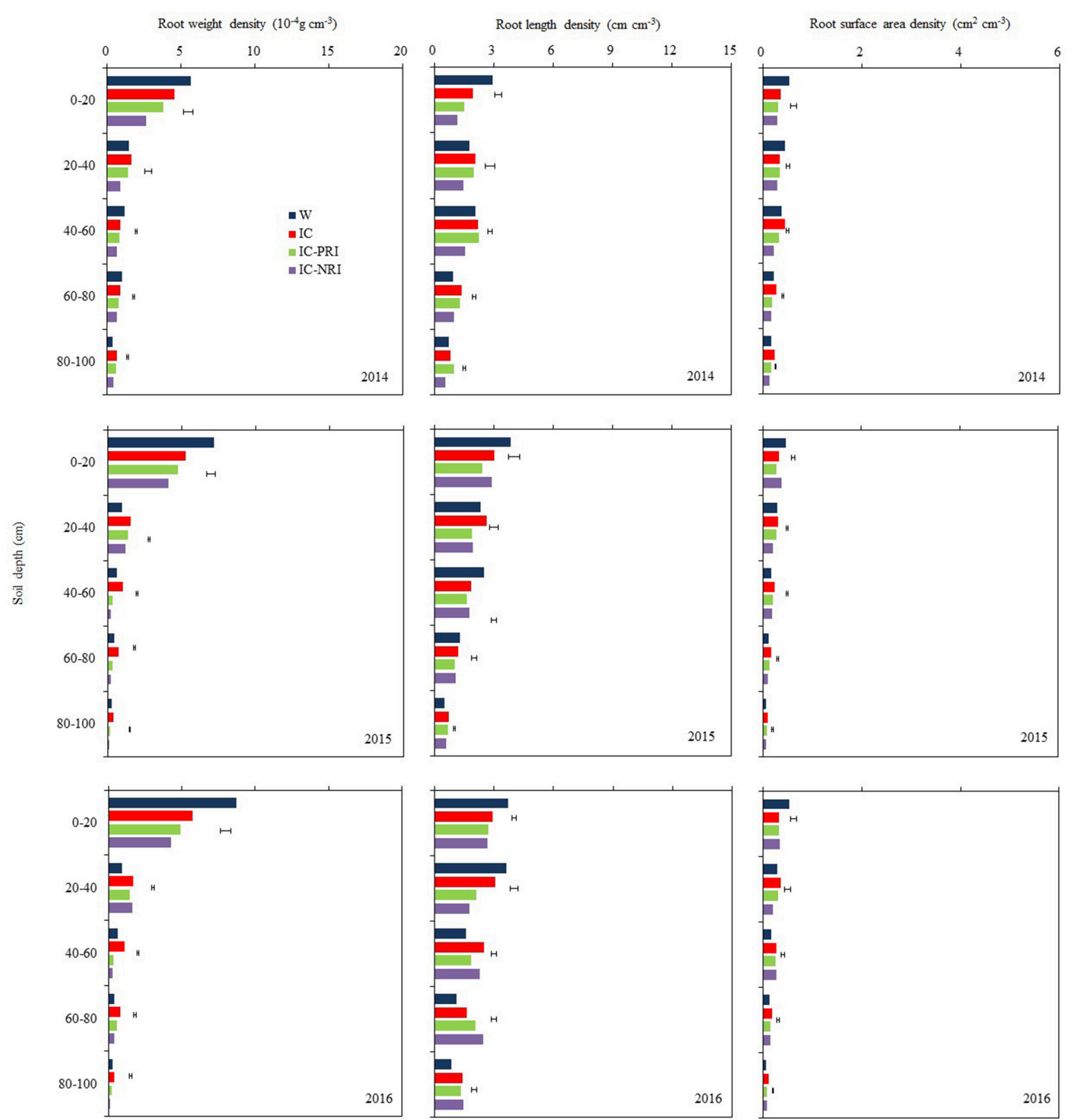

FIGURE 3 | The root weight density (RWD), root length density (RLD), and root surface area density (RSAD) of wheat at the wheat flowering stage, at Wuwei Experimental Station, in 2014, 2015, and 2016. W, single-cropped wheat; IC, wheat and maize intercropping with no root restrictions (i.e., no root barrier); IC-PRI, wheat and maize intercropping with partial root interaction (i.e., nylon mesh root barrier); IC-NRI, wheat and maize intercropping with no root interaction (i.e., plastic sheet root barrier); The line bars are least significant differences (LSDs), at the $P<0.05$ level, among the different treatments within each soil layer.

and $60-80-\mathrm{cm}$ soil layers increased, respectively, by 52,32 , and $23 \%$ in 2014 ; and 77,131 , and $21 \%$ in 2015 . In 2016 , however, there was no significant difference between high and low maize densities in affecting RWD for either of the soil layers. Complete belowground interaction with the high maize density increased the RWD of intercropped in the $60-80-\mathrm{cm}$ soil layer compared with the low maize density.

The response of maize RLD to the interspecies interaction treatments followed a similar trend as the effect on RWD but the treatment by year interaction on RLD was not significant, 


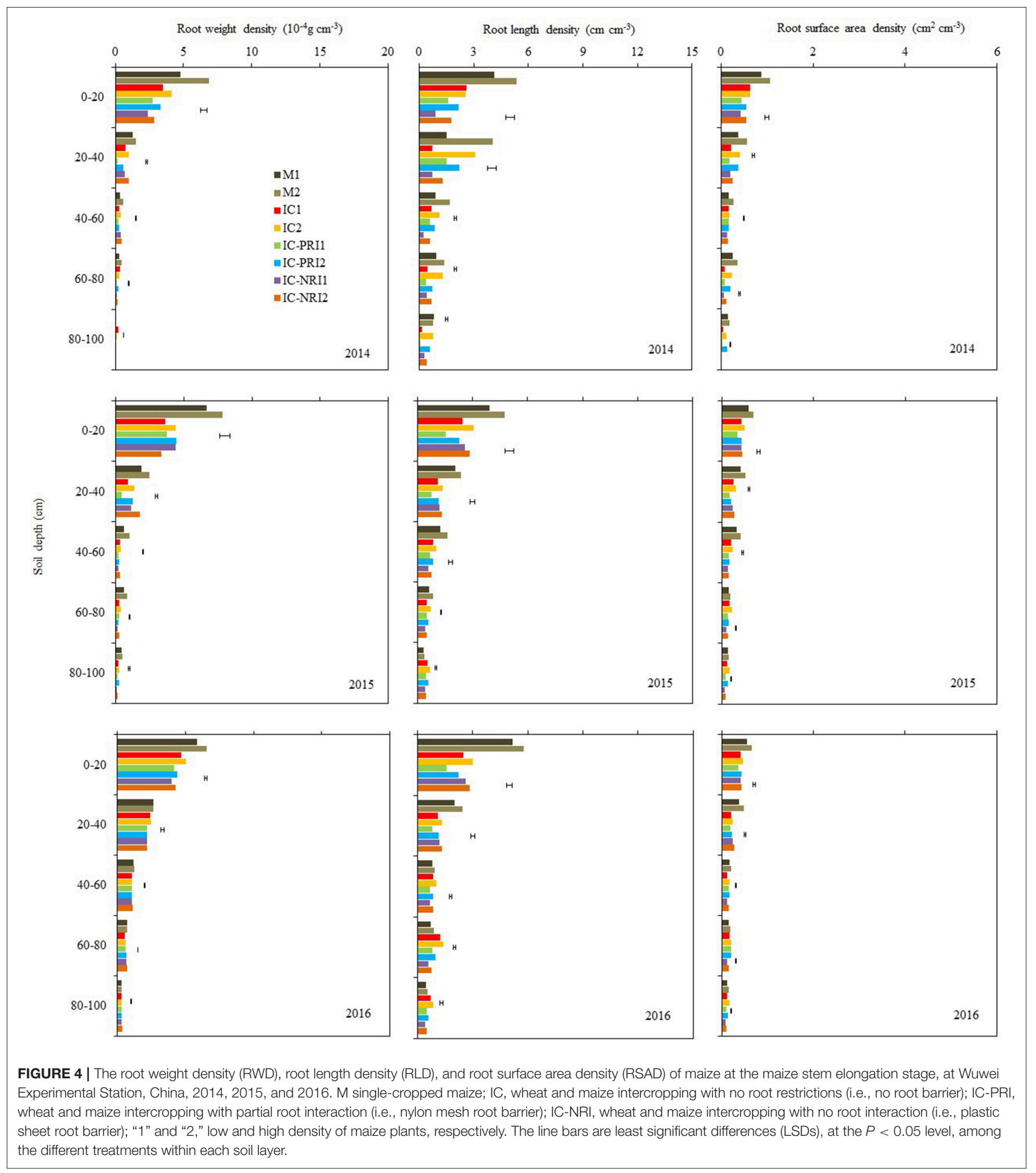

thus the average RLD across the three years are discussed here. In the $40-60,60-80$, and $80-100-\mathrm{cm}$ soil layers, the IC treatment increased maize RLD by 22,44 , and $33 \%$, respectively, as compared with the IC-PRI treatment (Figure 4); the maize
RLD under the IC treatment was 60,65 , and $48 \%$ greater than those under the IC-NRI treatment, respectively, for the three soil depths. In the $0-20$ and $20-40-\mathrm{cm}$ soil layer, the maize RLD in the IC treatment did not differ from that in the IC-NPR treatment, 
but increased by $42 \%$ in the $0-20$ soil layer and $28 \%$ in the $20-$ $40 \mathrm{~cm}$ soil layer compared with the IC-PRI treatment. The maize plants under the high density increased RLD by $24,56,40,52$, and $95 \%$, respectively, in the $0-20,20-40,40-60,60-80$, and $80-100$ $\mathrm{cm}$ soil layers, compared to the low plant density. The treatment of complete interspecies interaction in combination with high maize plant density achieved the highest RLD in the $40-100-\mathrm{cm}$ soil layer among all the treatments.

Complete belowground interactions in combination with high maize density significantly increased the RSAD in the most of the soil layers (Figure 4). On average, the maize in the IC treatment increased RSAD by 36,59 , and $197 \%$, respectively, in the 40 $60,60-80$, and $80-100-\mathrm{cm}$ soil layer, compared with the IC-NRI treatment; the maize in the IC-PRI treatment increased RSAD by 13,39 , and $175 \%$ in the three respective depths, compared with the IC-NRI treatment. However, in the $0-20$ and $20-40-\mathrm{cm}$ soil layers, the values of maize RSAD did not differ among the IC, IC-PRI, and IC-NRI treatments. The maize at the high density increased the RSAD by $14,33,17,59$, and $108 \%$, respectively, in the $0-20,20-40,40-60,60-80$, and $80-100-\mathrm{cm}$ soil layers, compared with the low density. The treatment of complete belowground interaction in combination with high maize density achieved the highest RSAD values in the $40-100-\mathrm{cm}$ soil layer among all treatments.

\section{Maize Root Development in Relation to Belowground Interactions After Wheat Harvest}

Maize roots were sampled for the second time at the beginning of grain development $(\mathrm{BBCH}=71)$, about 20 days after the wheat had been harvested. At this stage, the maize plants in the IC treatment had greater RWD, RLD, and RSAD compared with single-cropped maize (Figure 5). Averaged across the three study years, the maize in the IC treatment increased RWD, RLD, and RSAD by 40,44 , and $11 \%$, respectively, compared with singlecropped maize, whereas there were no significant differences in these values between the single-cropped maize and the IC-PRI or IC-NRI treatments.

Complete belowground interactions and increasing maize density increased RWD in the $0-80-\mathrm{cm}$ soil layer (Figure 5). On the three year average, the maize RWD in the IC treatment was $34,30,62$, and $17 \%$ greater than those in the IC-PRI treatment, respectively, in the $0-20,20-40$, and 40-60, and $60-80-\mathrm{cm}$ soil layers; and they were $50,81,221,116$, and $104 \%$ greater than those in the IC-NRI treatments, respectively, In the $80-100-\mathrm{cm}$ soil layer, there was no significant difference between the IC and IC-PRI treatments, whereas the RWD in the IC treatment was increased by $104 \%$ compared with the IC-NRI treatment. The maize under the high density increased RWD in the 0-20 soil layers by $10 \%$ in 2014 and $51 \%$ in 2016 , but no difference was found in 2015. In the $20-40,40-60,60-80$, and $80-100-\mathrm{cm}$ soil layers, the high density increased the maize RWD by 31,50 , 76 , and $55 \%$, respectively, on the average of three years. The complete belowground interaction, in combination with high maize density, led to the highest RWD in the $0-80-\mathrm{cm}$ soil layer, among all the treatments.
There was a significant interaction of belowground interaction treatment and maize density in affecting RLD of the intercropped maize but the effect followed a similar trend in each year. Averaged across the three year, RLD in the IC1 treatment was $73,26,54,80$, and $123 \%$ greater than that in the IC-NRI1 treatment in the $0-20,20-40,40-60,60-80$, and $80-100-\mathrm{cm}$ soil layers, respectively (Figure 5). Similarly, RLD in the IC2 treatment was $62,35,44,66$, and $89 \%$ greater than that in the IC-NRI1 treatment in the five respective soil layers. There was no significant difference in RLD between the IC-PRI and IC-NRI treatments in the $0-100-\mathrm{cm}$ soil layers. In the $0-20,20-40,40-60$, $60-80$, and $80-100-\mathrm{cm}$ soil layer, the maize in the IC treatment with the high density increased RLD by $16,21,20,32$, and $17 \%$, respectively, compared with the low density; similarly, the highdensity maize in the IC-PRI treatment increased RLD by 15,7 , 16,23 , and $18 \%$; and by $19,13,24,33$, and $33 \%$ in the IC-NRI treatment, compared with the low density. The high density with the complete belowground interaction had the highest RLD in the $0-100-\mathrm{cm}$ soil layer among all the treatments.

Complete belowground interactions and increasing maize density increased RSAD (Figure 5). There was no significant difference in RSAD between the IC and IC-PRI treatments, both being higher than that in the IC-NRI treatment. On three-year averages, in the $20-40,40-60,60-80$, and $80-100 \mathrm{~cm}$ soil layer, the RSAD in the IC treatment was, respectively, 16, 10, 13, and $8 \%$ higher compared with the IC-NRI treatment. Similarly, the RSAD in the IC-PRI treatment was 12 and $11 \%$ higher, respectively, in the $20-40$ and $60-80-\mathrm{cm}$ soil layers, compared with the IC-NRI treatment. With the increase in maize density, the maize RSAD increased by $11 \%$ only in the $0-20$ soil layers, across the three years. Thus, complete belowground interaction with the high maize density improved the RSAD of intercropped maize in the $0-20-\mathrm{cm}$ soil layer.

\section{Root Growth and Recovery of Maize After Wheat Harvest}

From the stem elongation to the grain-filling stage of maize, the roots of intercropped maize grew rapidly. Comparisons of the root growth rates (RGR) of the intercropped maize with those of single-cropped maize revealed that, after wheat harvest, intercropped maize had a significantly higher RGR than singlecropped maize (Table 3). Averaged across the three study years, the intercropped maize increased RGR by 138,85 , and $11 \%$ for RWD; by 110,105 , and $58 \%$ for RLD; and by 22,22 , and $12 \%$ for RSAD, in the IC, IC-PRI, and IC-NRI treatments, respectively, compared with the single-cropped maize. In general, the RGR for RWD, RLD, and RSAD increased by the largest percentage under complete belowground interaction. With the increase in maize plant density, the RGR for RWD increased proportionally. The RGR for RWD in the M, IC, IC-PRI, and IC-NRI treatments increased by $31,29,33$, and $43 \%$, respectively, with the high maize density. The RGR for RLD and RSAD tended to increase less. Thus, intercropping with complete belowground interaction at a higher planting density promoted RGR.

As defined in Equation (4) above, the recovery effect was expressed as the RGR value of intercropped maize divided by 


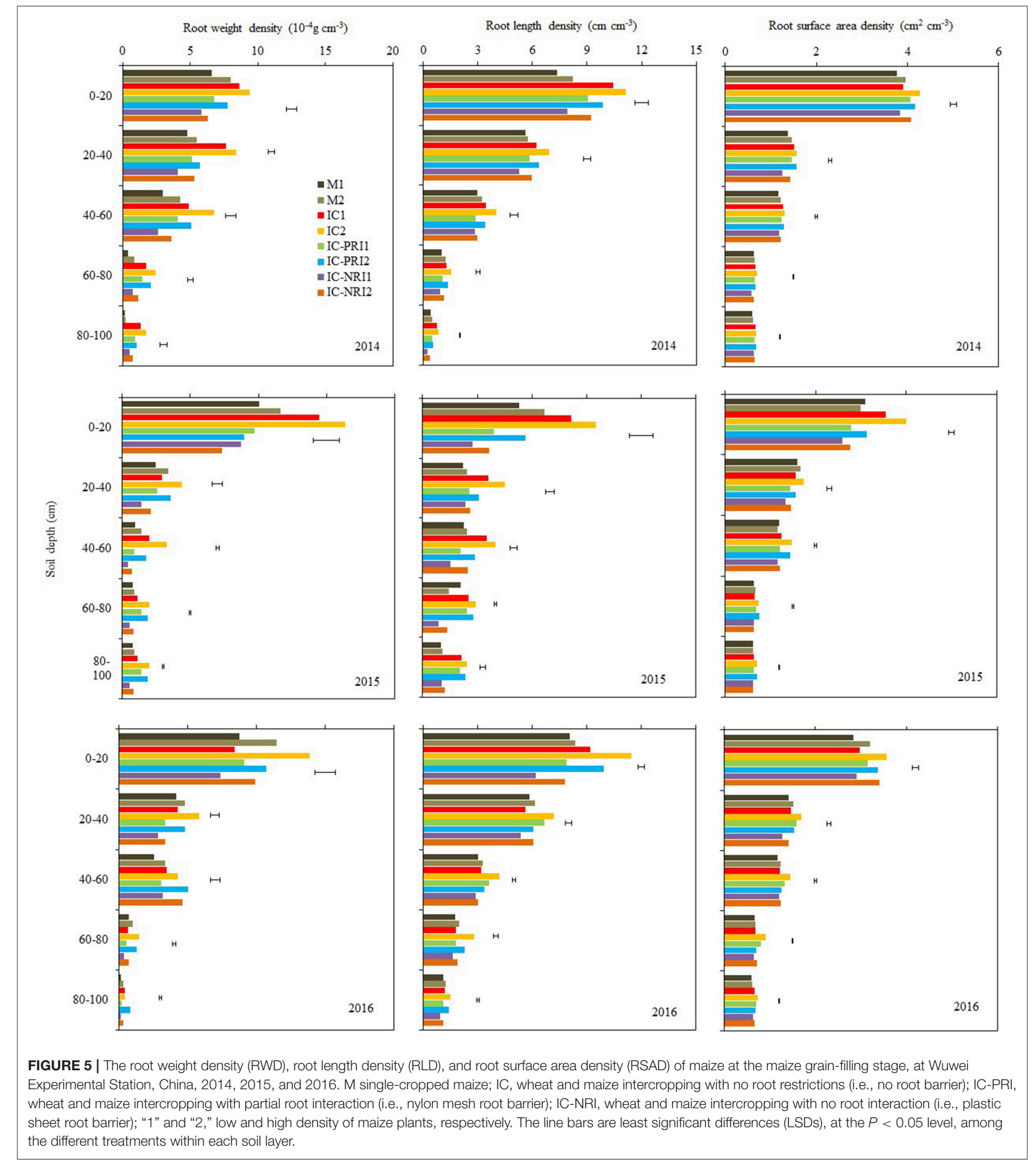

the RGR in the single-cropped maize. In the presented study, the 3-year average recovery effect for intercropped maize was $<1$, indicating that intercropped maize had a recovery effect following the harvest of the co-cropped wheat. The recovery effect in the IC treatment resulted in a 143 and 35\% increase in RWD compared with the IC-NRI and IC-PRI treatments, respectively (Table 4). Further, the recovery effect of RWD in the IC-PRI treatment was increased by $80 \%$ compared with 
TABLE 3 | Root growth rate (RGR) of maize plants from stem elongation (BBCH 31) to the grain filling $(\mathrm{BBCH} 71)$ under different treatments, with the root characteristics reflected by the root weight density (RWD), root length density (RLD), and root surface area density.

\begin{tabular}{|c|c|c|c|}
\hline \multirow[t]{2}{*}{ Treatment $^{a}$} & \multicolumn{3}{|c|}{ Root growth rate for the variable } \\
\hline & $\begin{array}{c}\text { RWD } \\
\left(10^{-4} \mathrm{~g} \mathrm{~cm}^{-3} \mathrm{~d}^{-1}\right)\end{array}$ & 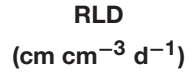 & $\begin{array}{c}\text { RSAD } \\
\left(\mathrm{cm}^{2} \mathrm{~cm}^{-3} \mathrm{~d}^{-1}\right)\end{array}$ \\
\hline M1 & 0.31 & 0.41 & 0.28 \\
\hline M2 & 0.40 & 0.34 & 0.27 \\
\hline IC1 & 0.74 & 0.78 & 0.32 \\
\hline IC2 & 0.95 & 0.79 & 0.34 \\
\hline$|\mathrm{C}-\mathrm{PR}| 1$ & 0.56 & 0.73 & 0.33 \\
\hline IC-PRI2 & 0.75 & 0.79 & 0.34 \\
\hline IC-NRI1 & 0.33 & 0.56 & 0.30 \\
\hline IC-NR2 & 0.46 & 0.62 & 0.31 \\
\hline$p$-value ${ }^{c}$ & $<0.01$ & $<0.01$ & $<0.01$ \\
\hline LSD (0.05) & 0.02 & 0.04 & 0.004 \\
\hline
\end{tabular}

${ }^{a} W$, single-cropped wheat; $M$ single-cropped maize; IC, intercropped wheat and maize with no root restrictions (i.e., no root barrier); IC-PRI, intercropped wheat and maize with partial root interaction (i.e., nylon mesh barrier); IC-NRI, intercropped wheat and maize with no root interaction (i.e., plastic sheet barrier); "1" and "2," low and high density of maize plants, respectively.

${ }^{b}$ The root growth rate reflected by the root weight density, root length density, and root area surface density for the total soil profile $(0-100 \mathrm{~cm})$; the values are averages of 2014, 2015, and 2016 because of no significant year $\times$ treatment interactions.

${ }^{c}$ The $p$-value and the LSD (0.05) were for all the treatments in a column.

the IC-NRI treatment. The recovery effect of RLD and RSAD showed trends similar to that of RWD. The recovery effect of RLD was affected by maize density. The recovery effect of RLD in the IC and IC-PRI treatments was increased by 30 and $37 \%$, respectively, with the increased maize density. In general, the complete belowground interaction with the high maize density promoted the root recovery. On the average of the three study years, the contribution rate due to belowground interspecies interaction was $143 \%$, the compensational effect due to root overlap was $35 \%$, and the CWN was $80 \%$, for the recovery effect of RWD.

\section{Grain Yield, Biomass, and Harvest Index}

Consistent grain yields were obtained over the three study years, with the intercropping systems having yield advantages over the corresponding single cropping (Table 5). On three years average, the total GY of intercropping was $137 \%$ greater compared with the corresponding single-cropped wheat, and was $14 \%$ greater compared with the single-cropped maize. The intercropped wheat produced $53 \%$ higher GY than the single-cropped wheat, and the intercropped maize produced 55\% higher GY that the single-cropped maize. The trend in biomass of each treatment was similar to that of grain yield.

Comparisons of the different belowground interaction patterns showed a significant yield increase with the complete belowground interaction in combination with the high maize density (Table 5). Averaged over the three study years, the complete belowground interaction contributed $20 \%$ GY increase,
TABLE 4 | Recovery effect (RE) of maize plants after wheat harvest under different treatments, with the root characteristics reflected by the root weight density (RWD), root length density (RLD), and root surface area density (RSAD).

\begin{tabular}{|c|c|c|c|}
\hline \multirow[t]{2}{*}{ Treatment $^{\mathrm{a}}$} & \multicolumn{3}{|c|}{ Recovery effect for the variable ${ }^{b}$} \\
\hline & $\mathrm{RWD}^{\mathrm{a}}$ & RLD & RSAD \\
\hline IC1 & 2.51 & 2.14 & 1.17 \\
\hline IC2 & 2.59 & 2.78 & 1.27 \\
\hline |C-PR|1 & 1.88 & 1.83 & 1.18 \\
\hline IC-PRI2 & 1.89 & 2.50 & 1.28 \\
\hline |C-NRI1 & 1.03 & 1.26 & 1.07 \\
\hline IC-NRI2 & 1.07 & 1.46 & 1.17 \\
\hline$p$-value ${ }^{c}$ & $<0.01$ & $<0.01$ & $<0.01$ \\
\hline $\operatorname{LSD}(0.05)^{\mathrm{b}}$ & 0.23 & 0.29 & 0.04 \\
\hline
\end{tabular}

${ }^{a} W$, single-cropped wheat; $M$ single-cropped maize; IC, intercropped wheat and maize with no root restrictions (i.e., no root barrier); IC-PRI, intercropped wheat and maize with partial root interaction (i.e., nylon mesh barrier); IC-NRI, intercropped wheat and maize with no root interaction (i.e., plastic sheet barrier); "1" and "2," low and high density of maize plants, respectively.

${ }^{b}$ The recovery effect of root weight density, root length density, and root area surface density for all soil profile $(0-100 \mathrm{~cm})$; the values are averages of 2014, 2015, and 2016 because of no significant year $x$ treatment interactions.

${ }^{c}$ The $p$-value and the LSD (0.05) were for all the treatments in a column.

and the high density contributed 7\% more GY than maize at the low density. Similarly, the CRO led to a $6 \%$ yield increase, and the effect was $4 \%$ greater with the high than the low maize density. The CWN led to a $13 \%$ yield increase, and the effect was $4 \%$ greater with the high than the low maize density.

Intercropped wheat had a greater HI with the higher maize density. The HI of wheat grown in the intercropping system was $12 \%$ greater in 2014 and $23 \%$ greater in 2016 compared with single-cropped wheat (Table 5). In contrast, the HI of intercropped maize was not significantly different from that of single-cropped maize. Among the three different belowground interaction treatments, partial belowground interaction in conjunction with the high maize density increased maize HI by $9 \%$ in 2014 and $42 \%$ in 2016, compared to the treatment with the treatment with no belowground interactions.

\section{DISCUSSION}

\section{Root Development in Relation to Above- and Below-Ground Interaction}

Numerous studies have shown that intercropping increases the productivity of the whole systems (Dahmardeh et al., 2010; Yang et al., 2010; Li L. et al., 2011; Li Q. Z. et al., 2011; Oshunsanya, 2013). However, the mechanisms responsible for the yield advantages of intercropping over sole planting are poorly understood. Sharing of available soil water and nutrients between the two crops during the co-growth period has been found to contribute positively to the yield advantage (Pandey et al., 2013), while at the meantime the two crops compete for the available resources at specific growth stages (Ghosh et al., 2006; Xu et al., 2013; Zhang et al., 2016). Yield advantage is typically related to root growth and development (Xu et al., 2010; 
TABLE 5 | Grain yield, biomass, and harvest index of wheat and maize in monoculture and wheat-maize intercropping under different root interaction treatments, at Wuwei Experimental Station, in 2014, 2015, and 2016.

\begin{tabular}{|c|c|c|c|c|c|c|c|c|}
\hline \multirow[b]{2}{*}{ Treatment } & \multicolumn{3}{|c|}{ Grain yield } & \multicolumn{3}{|c|}{ Biomass } & \multicolumn{2}{|c|}{ Harvest index } \\
\hline & Wheat & Maize & Total & Wheat & Maize & Total & Wheat & Maize \\
\hline \multicolumn{9}{|l|}{2014} \\
\hline W & 6,275 & - & 6,275 & 14,934 & - & 14,934 & 0.420 & - \\
\hline M1 & - & 11,501 & 11,501 & - & 23,765 & 23,765 & - & 0.484 \\
\hline M2 & - & 12,081 & 12,081 & - & 25,797 & 25,797 & - & 0.468 \\
\hline IC1 & 4,581 & 8,215 & 12,097 & 9,759 & 19,793 & 29,552 & 0.469 & 0.415 \\
\hline IC2 & 4,251 & 10,126 & 14,578 & 9,437 & 20,835 & 30,272 & 0.472 & 0.486 \\
\hline IC-PRI1 & 3,981 & 8,004 & 12,086 & 9,020 & 18,973 & 27,993 & 0.452 & 0.422 \\
\hline IC-PRI2 & 3,824 & 9,728 & 13,652 & 8,634 & 20,023 & 28,657 & 0.455 & 0.486 \\
\hline IC-NRI1 & 3,407 & 7,992 & 11,399 & 7,836 & 17,966 & 25,802 & 0.437 & 0.472 \\
\hline IC-NRI2 & 3,319 & 8,943 & 12,263 & 7,601 & 18,953 & 26,555 & 0.435 & 0.445 \\
\hline$P$-value ${ }^{\mathrm{a}}$ & $<0.01$ & $<0.01$ & $<0.01$ & $<0.01$ & $<0.01$ & $<0.01$ & $<0.01$ & $<0.01$ \\
\hline LSD (0.05) & 353 & 489 & 381 & 532 & 922 & 692 & 0.012 & 0.014 \\
\hline \multicolumn{9}{|l|}{2015} \\
\hline W & 6,070 & - & 6,070 & 15,650 & - & 15,650 & 0.390 & - \\
\hline M1 & - & 13,795 & 13,795 & - & 30,112 & 30,112 & - & 0.467 \\
\hline M2 & - & 12,819 & 12,819 & - & 31,366 & 31,366 & - & 0.447 \\
\hline IC1 & 4,434 & 9,149 & 13,584 & 10,843 & 19,211 & 30,055 & 0.410 & 0.447 \\
\hline IC2 & 4,514 & 10,807 & 15,322 & 10,922 & 23,012 & 33,935 & 0.413 & 0.463 \\
\hline IC-PRI1 & 4,002 & 8,758 & 12,761 & 10,422 & 18,771 & 29,193 & 0.386 & 0.476 \\
\hline IC-PRI2 & 3,917 & 9,852 & 13,769 & 10,308 & 22,054 & 32,362 & 0.380 & 0.469 \\
\hline IC-NRI1 & 3,451 & 8,149 & 11,600 & 9,632 & 17,614 & 27,246 & 0.360 & 0.409 \\
\hline IC-NRI2 & 3,609 & 8,435 & 12,045 & 9,696 & 18,852 & 28,548 & 0.373 & 0.458 \\
\hline$P$-value ${ }^{a}$ & $<0.01$ & $<0.01$ & $<0.01$ & $<0.01$ & $<0.01$ & $<0.01$ & $<0.01$ & $<0.01$ \\
\hline LSD (0.05) & 258 & 463 & 449 & 477 & 1,329 & 1,274 & 0.039 & 0.022 \\
\hline \multicolumn{9}{|l|}{2016} \\
\hline W & 6,313 & - & 6,313 & 16,748 & - & 16,748 & 0.372 & - \\
\hline M1 & - & 12,407 & 12,408 & - & 40,613 & 40,613 & - & 0.306 \\
\hline M2 & - & 15,307 & 15,307 & - & 43,477 & 43,477 & - & 0.286 \\
\hline IC1 & 5,327 & 10,421 & 15,781 & 10,900 & 25,127 & 36,028 & 0.461 & 0.395 \\
\hline IC2 & 5,400 & 11,816 & 17,203 & 10,613 & 34,930 & 45,543 & 0.459 & 0.326 \\
\hline IC-PRI1 & 5,026 & 9,934 & 14,926 & 11,059 & 22,344 & 33,403 & 0.482 & 0.466 \\
\hline IC-PRI2 & 4,876 & 11,381 & 16,271 & 11,167 & 20,930 & 32,097 & 0.484 & 0.565 \\
\hline IC-NRI1 & 4,718 & 8,037 & 12,722 & 9,865 & 15,625 & 25,491 & 0.478 & 0.514 \\
\hline IC-NRI2 & 4,475 & 9,107 & 13,626 & 9,581 & 22,836 & 32,417 & 0.467 & 0.399 \\
\hline$p$-value ${ }^{a}$ & $<0.01$ & $<0.01$ & $<0.01$ & $<0.01$ & $<0.01$ & $<0.01$ & $<0.01$ & $<0.01$ \\
\hline LSD (0.05) & 229 & 715 & 670 & 630 & 6,735 & 6,286 & 0.028 & 0.063 \\
\hline
\end{tabular}

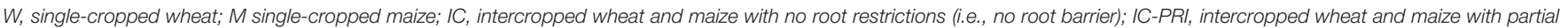

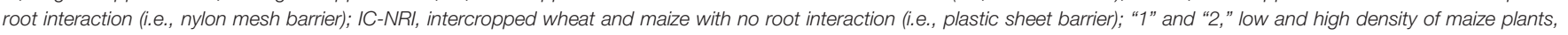
respectively.

a The $p$-value and the LSD (0.05) are for all treatments in each year.

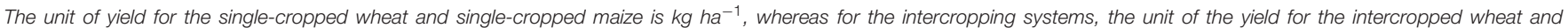

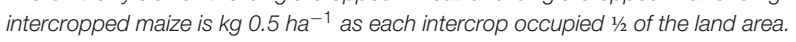

Wan et al., 2013), root distribution patterns across the rooting profile (Liu et al., 2015), and spatial variability in root traits. The root distribution patterns at the different soil depths vary with many factors, such as the morphological and physiological traits of the crops (Liu et al., 2010; Neykova et al., 2011), soil moisture (Smucker and Aiken, 1992) and nutrient contents, and plant density (Prasad and Brook, 2005). However, little information on the root characteristics of wheat-maize intercropping at different plant densities is available in the scientific literature. Working on the roots of intercropping is labor intensive and an added challenge is the difficulty of distinguishing and separating roots between the two intercrops. In the present study, we employed a modified monolith method with which the plant roots from the two intercrops were measured under 
the field conditions. Our results showed that the wheatmaize intercropping with no physically-inserted root barrier allowed a "complete belowground interaction" between the two intercropped species. This interspecies interaction promoted the root growth of intercropped maize significantly, reflected by the increased RWD, RLD, and root surface area density, compared with the corresponding sole cropping. Maize under a high plant density produced more roots that enhanced belowground interspecies interaction and increased crop productivity.

In interpreting the mechanisms of the yield advantages of intercropping over sole cropping in relation to root growth and distribution in the soil profile, one may consider the soil environments that affect the outcome of the belowground interspecies interactions. The growth and development of crop roots are closely related to the distribution of moisture and nutrients in the soil (Fan et al., 2016). Also, the spatial and temporal distributions of plant roots differ with crop species (Liu et al., 2011) and agronomic management practices (Vandoorne et al., 2012; Wang et al., 2012). Under dryland conditions, improving root distribution across the soil profile can enhance the crop water use efficiency (Wang et al., 2012) and thereby increasing crop productivity (Drew et al., 1973). Intercropping of crops with contrasting growth habits can improve primary resource use in both spatial and temporal contexts due to improved root distribution and connection between the species (Neykova et al., 2011). In many cases, the positive change in the soil environment brought about by one intercrop favors the growth of the other intercrop (Li et al., 2006).

\section{The Recovery Effect of Maize Roots}

Intercropping of an earlier-sown, cool-season crop (such as spring wheat) with a later-sown, warm-season crop (such as maize) offers many advantages for the use of natural resources (Feng et al., 2010; Yin et al., 2017). However, in this planting model, the growth of the later-sown crop is often restrained due to interspecific competition for space, soil water and nutrients. When one of the intercrops is harvested, the above- and belowground parts of the remaining crop have an expanded spatial environment, which is conducive to accelerate the growth (Li et al., 2006). In the wheat/maize intercropping system, maize is at a competitive disadvantage during the early part of the co-growth period, as the maize is planted later than the wheat. However, after wheat harvest, maize accelerates its growth, which compensates for the low competitiveness occurred during the co-growth period. This phenomenon is regarded as a "recovery effect" (Li et al., 2001a). In the present study, we quantified the recovery effect by determining the differences in root growth rate between the intercropped maize and the corresponding single-cropped maize during the wheat postharvest period. We found that the intercropped maize plants in the treatment with complete belowground interaction had a significantly higher total RWD than the single-cropped maize, leading to the recovery effect of the intercropped maize. This was in contrast to the observation at the stem elongation stage when the intercropped maize had a lower RWD than the single-cropped maize due to its poor competiveness with the intercropped wheat. The "recovery effect," reflected by the large increase of root growth traits (root length, weight, and surface area) of the intercropped maize, occurred during the wheat postharvest period when there was no longer "aboveground interspecies interaction." Our results showed that maize was capable of overcoming any earlyseason competitive disadvantage brought about by intercropping it with wheat. The belowground interspecies interactions are at least partially responsible for this recovery. The significantly increased maize root growth rate (compared with the singlecropped maize) after wheat harvest was largely attributable to the increased availability of space, soil water and nutrients as there was no longer any interspecies competition for the resources. Our findings support the hypothesis by other researchers that interspecific interactions promote root growth in intercropping systems (Li L. et al., 2011). However, with the experimental design in the present study, we were unable to determine whether the maize roots actually extended into the area occupied by the wheat roots after wheat harvest. Technically, it lacked of a ready-to-use technique with which the growing maize roots can be separated from the decomposing wheat roots in the wheat strips. It was assumed that the maize plants might be able to root into the soil volume occupied by the decomposing wheat roots (Gao et al., 2010), but the assumption needs to be verified.

The outcome of the "recovery effect" can be related to many factors. Our results showed that the density of the host plantmaize impacted the magnitude of the recovery effect, and a higher maize density enhanced the recovery effect of the intercropped maize due to increased root mass stimulating belowground interspecies interaction. In a previous study, we found that plant density had a significant effect on aboveground dry matter accumulation in intercropping (Yin et al., 2017), suggesting that the belowground interspecies interactions may also stimulate the growth of the aboveground plant parts. Furthermore, the outcome of the recovery effect may be related to other soilrelated factors because soil environments in the rooting zone are complex in nature and are affected by many factors, such as soil water availability (Niu et al., 2017), and soil physical (Luo et al., 2017), chemical (Grant et al., 2016), and biological (Taheri et al., 2016) properties. Agronomic practices may also affect the outcome of the recovery such as preceding crops in the rotation (Luce et al., 2016), tillage practices (Lupwayi et al., 2015), and soil microbial community structure and functionalities (Borrell et al., 2016). There is a need to elucidate those effects in the future studies to improve our understanding of the mechanisms responsible for the yield advantages of intercropping systems.

\section{The Correlation Between Root-Related Traits and Crop Yields}

Numerous studies have shown that intercropping systems increase crop yields significantly compared with corresponding monoculture. The increased yield is mostly attributable to increased soil water absorption and utilization (Fan et al., 2016), full use of belowground space (Agele, 2010; Devi et al., 2014), and improved rate of nutrient utilization (Levangbrilz and Biondini, 2003). Also, studies have revealed that root distribution affects crop growth and final yield (Li et al., 2001b; Kashiwagi et al., 
2006; Gao et al., 2010; Shiponeni et al., 2014). An overlapping of roots occurs in a two-crop intercropping system ( $\mathrm{Li}$ et al., 2006) which leads to greater root mass and higher crop yields (Yang et al., 2010). The enhanced root growth and development partially offsets the interspecific competitions for light (Amossé et al., 2013), heat (Knörzer et al., 2011), carbon dioxide (Shili Touzi et al., 2010), and other resources (Amossé et al., 2013; Dolijanović et al., 2013). A significant addition to the known features of intercropping systems from the present study is that belowground interspecies interactions, stimulated through the root growth and development of the intercrops, are partially responsible for the increased crop yield. Ecological principles indicate that competition and facilitation coexist simultaneously in a co-growing plant community. Our results showed that the belowground interspecies interaction helped overcome the competitive disadvantage of the maize encountered in the early co-growth period. In a previous study, we found that maize had a "super-compensation effect" for increasing the yield of the wheat/maize intercropping system but the mechanism was undetermined (Yin et al., 2017). Now, we understand that the "super-compensation effect" is partly attributable to the enhanced belowground interspecies interactions that help alleviate aboveground inter-plant competition.

\section{CONCLUSION}

Belowground interspecies interaction promoted the root growth and development as reflected by the increased root traits - RWD, $\mathrm{RLD}$, and RSAD in the intercropped maize. During the co-growth

\section{REFERENCES}

Agegnehu, G., Ghizaw, A., and Sinebo, W. (2008). Yield potential and land-use efficiency of wheat and faba bean mixed intercropping. Agron. Sustain. Dev. 28, 257-263. doi: 10.1051/agro:2008012

Agele, S. (2010). Dynamics of soil properties, soil fauna activity, pepper nutrition and fruit yield under plantain based intercropping system in a humid rainforest environment. Arch. Agron. Soil Sci. 56, 265-283. doi: 10.1080/03650340903092200

Ahmad, G., Mehdi, D., Barat, A. S., and Mahmoud, R. (2010). Effect of maize (Zea mays L.)-Cowpea (Vigna unguiculata L.) intercropping on light distribution, soil temperature and soil moisture in arid environment. J. Food Agric. Environ. 8, 102-108. Available online at: https://www.researchgate.net/publication/ 268411733_Effect_of_maize_Zea_mays_L_-_Cowpea_Vigna_unguiculata_L_ intercropping_on_light_distribution_soil_temperature_and_soil_moisture_ in_arid_environment

Amossé, C., Jeuffroy, M. H., and David, C. (2013). Relay intercropping of legume cover crops in organic winter wheat: effects on performance and resource availability. Field Crops Res. 145, 78-87. doi: 10.1016/j.fcr.2013.02.010

Beaver, R. J., and Melgar, M. (1999). Analysis of yield-density models for intercropping experiments. Biometrical J. 41, 995-1011. doi: 10.1002/ (SICI)1521-4036(199912)41:8\&lt;995::AID-BIMJ995\&gt;3.0.CO;2-H

Borrell, A. N., Shi, Y., Gan, Y., Bainard, L. D., Germida, J. J., and Hamel, C. (2016). Fungal diversity associated with pulses and its influence on the subsequent wheat crop in the Canadian prairies. Plant Soil 414, 13-31. doi: 10.1007/s11104-016-3075-y

Chai, Q., Qin, A. Z., Gan, Y. T., and Yu, A. Z. (2014). Higher yield and lower carbon emission by intercropping maize with rape, pea, and wheat in arid irrigation areas. Agron. Sustain. Dev. 34, 535-543. doi: 10.1007/s13593-013-0161-x period, the intercropped wheat had greater RWD, RLD, and RSAD than the single-cropped wheat across the $20-100 \mathrm{~cm}$ rooting zone. The intercropped maize had a lower RWD, RLD, and RSAD than single-cropped maize. At wheat postharvest, the intercropped maize increased RWD, RLD, and RSAD rapidly, enabling the "recovery effect" of the impaired maize growth experienced during the co-growth period, and the higher maize plant density enhanced the recovery effect. Comparisons for the differences in root weight between intercropped maize and single-cropped maize gave a quantitative assessment of the recovery effect: the belowground interspecies interaction contributed $143 \%$ to the recovery effect, the CRO contributed $35 \%$, and the CWN contributed $80 \%$. A complete belowground interaction is the key to promote the recovery effect, and a high maize density enhances the recovery effect.

\section{AUTHOR CONTRIBUTIONS}

QC and YW conceived and designed the experiment; YW, QC, and FF performed the statistical analyses; YW, YQ, AY, and CZ were involved in field data collection. All authors contributed to writing the manuscript.

\section{ACKNOWLEDGMENTS}

This study was supported by the National Natural Science Foundation of China $(31360323,31771738)$. We would like to thank Aziiba Emmanuel Asibi for improving the use of English in this manuscript.

Dahmardeh, M., Ghanbari, A., Syahsar, B. A., and Ramrodi, M. (2010). The role of intercropping maize (Zea mays L.) and cowpea (Vigna unguiculata L.) on yield and soil chemical properties. Afr. J. Agr. Res. 5, 631-636. doi: 10.5897/AJAR09.607

Devi, K. N., Shamurailatpam, D., Singh, T. B., Athokpam, H. S., Singh, N. B., Singh, N. G., et al. (2014). Performance of lentil (Lens culinaris M.) and mustard (Brassica juncea L.) intercropping under rainfed conditions. Aust. J. Crop Sci. 8, 284-289. Available online at: https://www.researchgate. net/publication/259475493_Performance_of_lentil_Lens_culinaris_M_and_ mustard_Brassica_juncea_L_intercropping_under_rainfed_conditions

Dolijanović, Z., Oljača, S., Kovacević, D., Simić, M., Momirović, N., and Jovanović, Z. (2013). Dependence of the productivity of maize and soybean intercropping systems on hybrid type and plant arrangement pattern. Genet. Belgr. 45, 135-144. doi: 10.2298/GENSR1301135D

Drew, M. C., Saker, L. R., and Ashley, T. W. (1973). Nutrient supply and the growth of the seminal root system in barley I. The effect of nitrate concentration on the growth of axes and laterals. J. Exp. Bot. 24, 1189-1202. doi: $10.1093 / \mathrm{jxb} / 24.6 .1189$

Fan, J., Mcconkey, B., Wang, H., and Janzen, H. (2016). Root distribution by depth for temperate agricultural crops. Field Crops Res. 189, 68-74. doi: $10.1016 /$ j.fcr.2016.02.013

Fan, Z. L., Chai, Q., Huang, G. B., Yu, A. Z., Huang, P., Yang, C. H., et al. (2013). Yield and water consumption characteristics of wheat/maize intercropping with reduced tillage in an Oasis region. Eur. J. Agron. 45, 52-58. doi: 10.1016/j.eja.2012.10.010

Feng, F. X., Huang, G. B., Chai, Q., and Yu, A. Z. (2010). Tillage and straw management impacts on soil properties, root growth, and grain yield of winter wheat in Northwestern China. Crop Sci. 50, 1465-1473. doi: $10.2135 /$ cropsci2008.10.0590 
Gan, Y. T., Siddique, K. H. M., Turner, N. C., Li, X. G., Niu, J. Y., Yang, C., et al. (2013). Chapter seven-ridge-furrow mulching systems-an innovative technique for boosting crop productivity in semiarid rain-fed environments. Adv. Agron. 118, 429-476. doi: 10.1016/B978-0-12-405942-9.00007-4

Gao, Y., Duan, A. W., Qiu, X. Q., Liu, Z. G., Sun, J. S., Zhang, J. P., et al. (2010). Distribution of roots and root length density in a maize/soybean strip intercropping system. Agr. Water Manage. 98, 199-212. doi: 10.1016/j.agwat.2010.08.021

Ghosh, P. K., Mohanty, M., Bandyopadhyay, K. K., Painuli, D. K., and Misra, A. K. (2006). Growth, competition, yields advantage and economics in soybean/pigeonpea intercropping system in semi-arid tropics of India: II. Effect of nutrient management. Field Crops Res. 96, 90-97. doi: 10.1016/j.fcr.2005.05.010

Grant, C. A., O’Donovan, J. T., Blackshaw, R. E., Harker, K. N., Johnson, E. N., Gan, Y. T., et al. (2016). Residual effects of preceding crops and nitrogen fertilizer on yield and crop and soil $\mathrm{N}$ dynamics of spring wheat and canola in varying environments on the Canadian prairies. Field Crops Res. 192, 86-102. doi: 10.1016/j.fcr.2016.04.019

Hu, F. L., Chai, Q., Yu, A. Z., Yin, W., Cui, H. G., and Gan, Y. T. (2014). Less carbon emissions of wheat-maize intercropping under reduced tillage in arid areas. Agron. Sustain. Dev. 35, 701-711. doi: 10.1007/s13593-014-0257-y

Hu, F. L., Gan, Y. T., Cui, H. Y., Zhao, C., Feng, F. X., Yin, W., et al. (2016). Intercropping maize and wheat with conservation agriculture principles improves water harvesting and reduces carbon emissions in dry areas. Eur. J. Agron. 74, 9-17. doi: 10.1016/j.eja.2015.11.019

Hu, X. T., Chen, H., Wang, J., Meng, X. B., and Chen, F. H. (2009). Effects of soil water content on cotton root growth and distribution under mulched drip irrigation. Agr. Sci. China 8, 709-716. doi: 10.1016/S1671-2927(08)60269-2

Kashiwagi, J., Krishnamurthy, L., Crouch, J. H., and Serraj, R. (2006). Variability of root length density and its contributions to seed yield in chickpea (Cicer arietinum L.) under terminal drought stress. Field Crop Res. 95, 171-181. doi: 10.1016/j.fcr.2005.02.012

Knörzer, H., Grözinger, H., Graeff-Hönninger, S., Hartung, K., Piepho, H. P., and Claupein, W. (2011). Integrating a simple shading algorithm into CERES-wheat and CERES-maize with particular regard to a changing microclimate within a relay-intercropping system. Field Crops Res. 121, 274-285. doi: 10.1016/j.fcr.2010.12.016

Landhäusser, S. M., Lieffers, V. J., and Mulak, T. (2006). Effects of soil temperature and time of decapitation on sucker initiation of intact Populus tremuloides root systems. Scand. J. Forest Res. 21, 299-305. doi: 10.1080/02827580600813313

Levangbrilz, N., and Biondini, M. E. (2003). Growth rate, root development and nutrient uptake of 55 plant species from the Great Plains Grasslands, USA. Plant Ecol. 165, 117-144. doi: 10.1023/A:1021469210691

Li, L., Sun, J. H., and Zhang, F. S. (2011). Intercropping with wheat leads to greater root weight density and larger below-ground space of irrigated maize at late growth stages. Soil Sci. Plant Nutr. 57, 61-67. doi: 10.1080/00380768.2010.548307

Li, L., Sun, J. H., Zhang, F. S., Li, X. L., Rengel, Z., and Yang, S. C. (2001a). Wheat/maize or wheat/soybean strip intercropping. II. Recovery or compensation of maize and soybean after wheat harvesting. Field Crops Res. 71, 173-181. doi: 10.1016/S0378-4290(01)00157-5

Li, L., Sun, J. H., Zhang, F. S., Li, X. L., Yang, S. C., and Rengel, Z. (2001b). Wheat/maize or wheat/soybean strip intercropping : I. Yield advantage and interspecific interactions on nutrients. Field Crops Res. 71, 123-137. doi: 10.1016/S0378-4290(01)00156-3

Li, L., Sun, J., Zhang, F., Guo, T., Bao, X., Smith, F. A., et al. (2006). Root distribution and interactions between intercropped species. Oecologia 147, 280-290. doi: 10.1007/s00442-005-0256-4

Li, Q. Z., Sun, J. H., Wei, X. J., Christie, P., Zhang, F. S., and Li, L. (2011). Overyielding and interspecific interactions mediated by nitrogen fertilization in strip intercropping of maize with faba bean, wheat and barley. Plant Soil 339, 147-161. doi: 10.1007/s11104-010-0561-5

Liu, L., Gan, Y., Bueckert, R., Van Rees, K., and Warkentin, T. (2010). Fine root distributions in oilseed and pulse crops. Crop Sci. 50, 222-226. doi: $10.2135 /$ cropsci2009.03.0156

Liu, L., Gan, Y. T., Bueckert, R., and Van Rees, K. (2011). Rooting systems of oilseed and pulse crops I: temporal growth patterns across the plant developmental periods. Field Crops Res. 122, 256-263. doi: 10.1016/j.fcr.2011.04.002
Liu, Y. X., Zhang, W. P., Sun, J. H., Li, X. F., Christie, P., and Li, L. (2015). High morphological and physiological plasticity of wheat roots is conducive to higher competitive ability of wheat than maize in intercropping systems. Plant Soil 397, 387-399. doi: 10.1007/s11104-015-2654-7

Luce, M. S., Grant, C. A., Ziadi, N., Zebarth, B. J., O'donovan, J. T., Blackshaw, R. E., et al. (2016). Preceding crops and nitrogen fertilization influence soil nitrogen cycling in no-till canola and wheat cropping systems. Field Crops Res. 191, 20-32. doi: 10.1016/j.fcr.2016.02.014

Luo, Z., Gan, Y., Niu, Y., Zhang, R., Li, L., Cai, L., et al. (2017). Soil quality indicators and crop yield under long-term tillage systems. Exp. Agric. 53, 497-511. doi: 10.1017/S0014479716000521

Lupwayi, N. Z., Harker, K. N., O’donovan, J. T., Turkington, T. K., Blackshaw, R. E., Hall, L. M., et al. (2015). Relating soil microbial properties to yields of no-till canola on the Canadian prairies. Eur. J. Agron. 62, 110-119. doi: 10.1016/j.eja.2014.10.004

Muoneke, C. O., Ogwuche, M. A. O., and Kalu, B.A. (2007). Effect of maize planting density on the performance of maize/soybean intercropping system in a guinea savannah agroecosystem. Afr. J. Agr. Res. 2, 667-677. Available online at: https://www.researchgate.net/publication/228667314_Effect_of_maize_ planting_density_on_the_performance_of_maizesoybean_intercropping system_in_a_guinea_savannah_agroecosystem

Neykova, N., Obando, J., Schneider, R., Shisanya, C., Thiele, B. S., and Thomas, F. M. (2011). Vertical root distribution in single-crop and intercropping agricultural systems in Central Kenya. J. Plant Nutr. Soil Sci. 174, 742-749. doi: 10.1002/jpln.201000314

Niu, Y. N., Bainard, L., Bandara, M. S., Hamel, C., and Gan, Y. T. (2017) Soil residual water and nutrients explain about $30 \%$ of the rotational effect in 4-year pulse-intensified rotation systems. Can. J. Plant Sci. 97, 852-864. doi: 10.1139/CJPS-2016-0282

Ong, C. K. (1995). The "dark side" of Intercropping: manipulation of soil resources," in Ecophysiology of Tropical Intercropping, eds H. Sinoquet and P. Cruz (Paris: INPR), 45-66.

Oshunsanya, S. O. (2013). Spacing effects of vetiver grass (Vetiveria nigritana Stapf) hedgerows on soil accumulation and yields of maizecassava intercropping system in Southwest Nigeria. Catena 104, 120-126. doi: 10.1016/j.catena.2012.10.019

Pandey, I. B., Singh, S. K., and Tiwari, S. (2013). Integrated nutrient management for sustaining the productivity of pigeonpea (Cajanus cajan) based intercropping systems under rainfed condition. Indian J. Agron. 58, 192-197. Available online at: https://www.researchgate.net/publication/289573564_ Integrated_nutrient_management_for_sustaining_the_productivity_of_ pigeonpea_Cajanus_cajan_based_intercropping_systems_under_rainfed_ condition

Prasad, R. B., and Brook, R. M. (2005). Effect of varying maize densities on intercropped maize and soybean in Nepal. Exp. Agr. 41, 365-382. doi: 10.1017/S0014479705002693

Qin, A. Z., Huang, G. B., Chai, Q., Yu, A. Z., and Huang, P. (2013). Grain yield and soil respiratory response to intercropping systems on arid land. Field Crop Res. 144, 1-10. doi: 10.1016/j.fcr.2012.12.005

Romero, P., Gil-Muñoz, R., Del Amor, F. M., Valdés, E., Fernández, J. I., and Martinez-Cutillas, A. (2013). Regulated deficit irrigation based upon optimum water status improves phenolic composition in monastrell grapes and wines. Agr. Water Manage. 121, 85-101. doi: 10.1016/j.agwat.2013.01.007

Schenk, H. J. (2006). Root competition: beyond resource depletion. J. Ecol. 94, 725-739. doi: 10.1111/j.1365-2745.2006.01124.x

Shili Touzi, I., De Tourdonnet, S., Launay, M., and Dore, T. (2010). Does intercropping winter wheat (Triticum aestivum) with red fescue (Festuca rubra) as a cover crop improve agronomic and environmental performance? A modeling approach. Field Crops Res. 116, 218-229. doi: $10.1016 /$ j.fcr.2009.11.007

Shiponeni, N. N., Carrick, P. J., Allsopp, N., Hoffman, M. T., and Ward, D. (2014) Effects of root competition and soils on seedling establishment at the ecotone between an arid grassland and succulent shrubland in South Africa. J. Veg. Sci. 25, 402-410. doi: 10.1111/jvs.12082

Smit, A. L., Bengough, A. G., Engels, C., Noordwijk, M. V., Pellerin, S., and Geijn, S. C. (2000). Root Methods a Hand Book. Heidelberg: Springer.

Smucker, A. J. M., and Aiken, R. M. (1992). Dynamic root responses to water deficits. Soil Sci. 154, 281-289. doi: 10.1097/00010694-199210000-00004 
Taheri, A. E., Hamel, C., and Gan, Y. T. (2016). Cropping practices impact fungal endophytes and pathogens in durum wheat roots. Appl. Soil Ecol. 100, 104-111. doi: 10.1016/j.apsoil.2015.12.007

Vandermeer, J. H. (1989). The Ecology of Intercropping. Cambridge: Cambridge University Press.

Vandoorne, B., Mathieu, A. S., Van Den Ende, W., Vergauwen, R., Périlleux, C., Javaux, M., et al. (2012). Water stress drastically reduces root growth and inulin yield in Cichorium intybus (var. sativum) independently of photosynthesis. J. Exp. Bot. 63, 4359-4373. doi: 10.1093/jxb/ers095

Wan, Y., Yan, Y. H., Yang, T. W., Liu, W. G., and Wang, X. C. (2013). Responses of root growth and nitrogen transfer metabolism to uniconazole, a growth retardant, during the seedling stage of soybean under relay strip intercropping system. Commun. Soil Sci. Plant 44, 3267-3280. doi: 10.1080/00103624.2013.840838

Wang, H., Inukai, Y., and Yamauchi, A. (2006). Root development and nutrient uptake. Crit Rev in Plant Sci. 25, 279-301. doi: 10.1080/07352680600709917

Wang, X., Gan, Y., Hamel, C., Lemke, R., and Mcdonald, C. (2012). Water use profiles across the rooting zones of various pulse crops. Field Crops Res. 134, 130-137. doi: 10.1016/j.fcr.2012.06.002

Wilson, J. B. (1988). Shoot competition and root competition. J. Appl. Ecol. 25, 279-296. doi: $10.2307 / 2403626$

$\mathrm{Xu}, \mathrm{B}$., Li, F., and Shan, L. (2010). Seasonal root biomass and distribution of switchgrass and milk vetch intercropping under 2:1 row replacement in a semiarid region in Northwest China. Commun. Soil Sci. Plant 41, 1959-1973. doi: 10.1080/00103624.2010.495806

Xu, H., Bi, H., Gao, L., Yun, L., Chang, Y., Xi, W., et al. (2013). Distribution and morphological variation of fine root in a walnut-soybean intercropping system in the loess plateau of china. Int. J. Agric. Biol. 15, 998-1002. Available online at: https://www.researchgate.net/publication/288456398_Distribution_and_ morphological_variation_of_fine_root_in_a_walnut-soybean_intercropping_ system_in_the_loess_plateau_of_china
Yang, C. H., Chai, Q., and Huang, G. B. (2010). Root distribution and yield responses of wheat/maize intercropping to alternate irrigation in the arid areas of northwest China. Plant Soil Environ. 56, 253-262. doi: 10.17221/251/2009-PSE

Yin, W., Chen, G. P., Feng, F. X., Guo, Y., Hu, F. L., Chen, G. D., et al. (2017). Straw retention combined with plastic mulching improves compensation of intercropped maize in arid environment. Field Crop Res. 204, 42-51. doi: 10.1016/j.fcr.2017.01.005

Yin, W., Yu, A. Z., Chai, Q., Hu, F. L., Feng, F. X., and Gan, Y. T. (2015). Wheat and maize relay-planting with straw covering increases water use efficiency up to 46\%. Agron. Sustain. Dev. 35, 815-825. doi: 10.1007/s13593-0150286-1

Zhang, F. S., and Li, L. (2003). Using competitive and facilitative interactions in intercropping systems enhances crop productivity and nutrient-use efficiency. Plant Soil 248, 305-312. doi: 10.1023/A:1022352229863

Zhang, W. P., Liu, G. C., Sun, J. H., Fornara, D., Zhang, L. Z., Zhang, F. F., et al. (2016). Temporal dynamics of nutrient uptake by neighbouring plant species: Evidence from intercropping. Funct. Ecol. 31, 469-479. doi: $10.1111 / 1365-2435.12732$

Conflict of Interest Statement: The authors declare that the research was conducted in the absence of any commercial or financial relationships that could be construed as a potential conflict of interest.

Copyright (c) 2018 Wang, Qin, Chai, Feng, Zhao and Yu. This is an open-access article distributed under the terms of the Creative Commons Attribution License (CC $B Y)$. The use, distribution or reproduction in other forums is permitted, provided the original author(s) and the copyright owner are credited and that the original publication in this journal is cited, in accordance with accepted academic practice. No use, distribution or reproduction is permitted which does not comply with these terms. 